Supporting Information (SI)

\title{
Modular Peptide Probe for Pre/Intra/Postoperative Therapeutic to Reduce Recurrence in Ovarian Cancer
}

Jun Dai, ${ }^{\dagger a}$ Yong Cheng,${ }^{\dagger b}$ Jun Wu, ${ }^{\dagger b}$ Quan Wang, ${ }^{b}$ Wenwen Wang, ${ }^{a}$ Juliang Yang, ${ }^{b}$ Zujin Zhao, ${ }^{c}$ Xiaoding Lou ${ }^{* b}$ Fan Xia, ${ }^{* b}$ Shixuan Wang, ${ }^{* a}$ Ben Zhong Tang, ${ }^{c}$

${ }^{a}$ Department of Obstetrics and Gynecology, Tongji Hospital, Tongji Medical College, Huazhong University of Science and Technology, Wuhan 430074, China. Email: shixuanwang@tjh.tjmu.edu.cn

${ }^{b}$ Engineering Research Center of Nano-Geomaterials of Ministry of Education, Faculty of Materials Science and Chemistry, China University of Geosciences, Wuhan 430078, China. E-mail: louxiaoding@cug.edu.cn; xiafan@cug.edu.cn

${ }^{\text {c} S t a t e ~ K e y ~ L a b o r a t o r y ~ o f ~ L u m i n e s c e n t ~ M a t e r i a l s ~ a n d ~ D e v i c e s, ~ S o u t h ~ C h i n a ~ U n i v e r s i t y ~ o f ~}$ Technology, Guangzhou 510640, China.

${ }^{\dagger}$ These authors contribute equally to this work. 


\section{Contents}

\section{Additional table}

Table s1

\begin{tabular}{|c|c|}
\hline Full name & Abbreviation \\
\hline preoperative GT, surgery and intraoperative PDT & $\mathrm{miR} / \mathrm{Surg} / \mathrm{PDT}$ \\
\hline preoperative GT, surgery, intraoperative PDT and postoperative GT & $\mathrm{miR} / \mathrm{Surg} / \mathrm{PDT} / \mathrm{siVEGF}$ \\
\hline matrix metallopeptidase 2 & MMP-2 \\
\hline nanoparticles & NPs \\
\hline photodynamic therapy & PDT \\
\hline $\begin{array}{l}\text { Preoperative (TCDTMP/miR-145-5p) } \| \text { Intraoperative (Surgery and } \\
\text { PDT) } \| \text { Postoperative (TCDTMP/VEGF-siRNA) therapeutic system }\end{array}$ & PIP \\
\hline reactive oxygen species & ROS \\
\hline surgery & Surg \\
\hline surgery and intraoperative PDT & Surg/PDT \\
\hline tumor molecular targeted peptide 1 & TMTP1 \\
\hline $\begin{array}{l}\text { TMTP1 (cyclic D-peptide) +TAT peptide +MMP-2 cleavage site } \\
\text { +PyTPA }\end{array}$ & $\mathrm{T}_{\mathrm{CD}} \mathrm{TMP}$ \\
\hline $\begin{array}{l}\text { TMTP1 (cyclic D-peptide) +TAT peptide +MMP-2 cleavage site } \\
\text { +PyTPA }\end{array}$ & $\mathrm{T}_{\mathrm{CD}} \mathrm{TMF}$ \\
\hline $\begin{array}{l}\text { TMTP1 (cyclic L-peptide) +TAT peptide +MMP-2 cleavage site } \\
\text { +PyTPA }\end{array}$ & $\mathrm{T}_{\mathrm{CL}} \mathrm{TMP}$ \\
\hline TMTP1 (cyclic D-peptide) +MMP-2 cleavage site +PyTPA & $\mathrm{T}_{\mathrm{CD}} \mathrm{MP}$ \\
\hline TAT peptide + MMP-2 cleavage site + PyTPA & TMP \\
\hline
\end{tabular}




\section{Additional figures}

\section{Scheme s1}

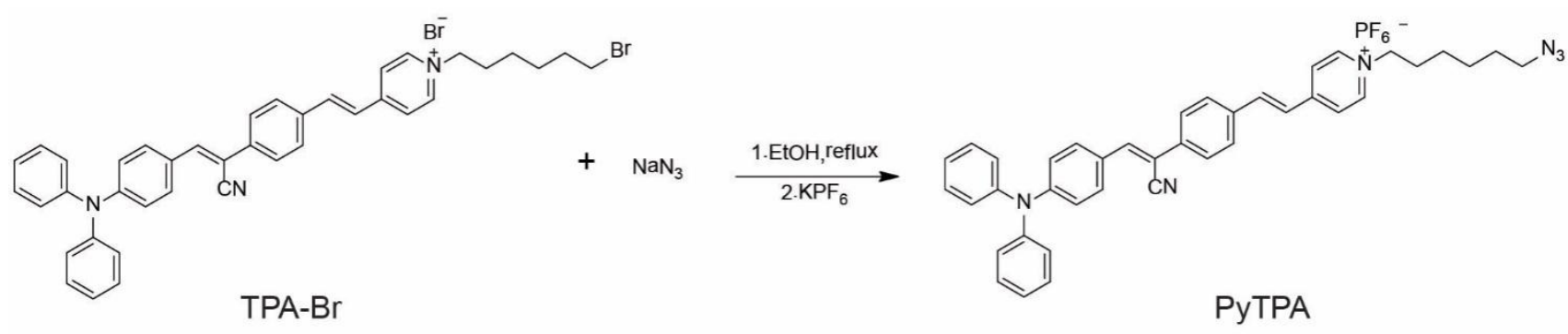

Scheme s1. The synthetic routes of PyTPA. Compound TPA-Br $(860.58 \mathrm{mg}, 1.2 \mathrm{mmol})$ and $\mathrm{NaN}_{3}$ (130 mg, $2 \mathrm{mmol})$ were refluxed in acetonitrile $(20 \mathrm{~mL})$ for 24 hours. Then the reaction mixture was diluted with acetic ether and washed with water $(10 \mathrm{~mL} \times 2)$, brine $(10 \mathrm{~mL})$, finally dried with magnesium sulfate. The solvent was evaporated under reduced pressure. The solid was dissolved in acetone $(5 \mathrm{~mL})$ and a saturated aqueous solution of $\mathrm{KPF}_{6}(5 \mathrm{~mL})$ was then added. After stirring for 30 minutes, the solution was evaporated to dryness. The residue was purified by silica gel column chromatography using dichloromethane and methyl alcohol mixture ( $\mathrm{v}: \mathrm{v}=10: 1)$ as eluent to give PyTPA as a red product. Yield: 95\%. ${ }^{1} \mathrm{H}$ NMR (400 MHz, $\left.\mathrm{CDCl}_{3}\right), \delta(\mathrm{TMS}, \mathrm{ppm}): 8.75(\mathrm{t}, 2 \mathrm{H}), 7.92$ (t, 2H), $7.58(\mathrm{t}, 1 \mathrm{H}), 7.38(\mathrm{t}, 2 \mathrm{H}), 7.13(\mathrm{~d}, 1 \mathrm{H}), 7.04-7.15(\mathrm{~m}, 9 \mathrm{H}), 7.03(\mathrm{~d}, 2 \mathrm{H}), 7.00-7.02(\mathrm{~m}, 6 \mathrm{H})$, $4.63(\mathrm{t}, 2 \mathrm{H}), 3.43(\mathrm{t}, 2 \mathrm{H}), 2.01-2.10(\mathrm{~m}, 2 \mathrm{H}), 1.63-1.72(\mathrm{~m}, 2 \mathrm{H}) .{ }^{13} \mathrm{C} \mathrm{NMR}\left(100 \mathrm{MHz}, \mathrm{CDCl}_{3}\right) \delta$ 213.97, 187.21, 186.76, 172.22, 170.96, 161.07, 156.26, 155.73, 135.80, 135.56, 134.08, 133.64, $128.59,127.69,127.01,120.92,119.90,118.43,111.63,111.44,100.79,69.76,69.50,67.20,65.59$, $65.43,56.70,44.98,37.66,36.42,35.75,33.98,29.94,28.22,26.19,25.35,25.01,16.85$. HR-MS (MALDI-TOF): [M] $]^{+}$calcd for $\mathrm{C}_{40} \mathrm{H}_{37} \mathrm{~N}_{6}, 601.3080$; found, 601.3092. 


\section{Scheme s2}

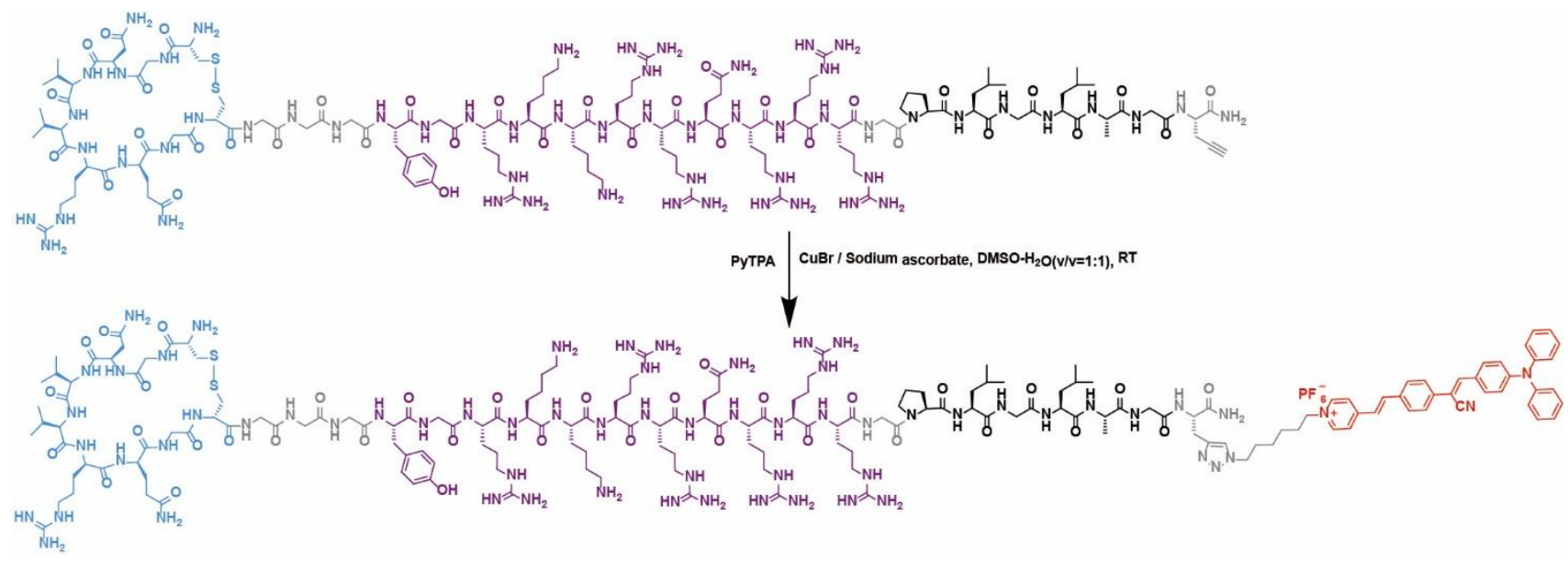

Scheme s2. The synthetic routes of TCDTMP. PyTPA (10.0 mg, 12.7 mol, 1.5 equiv.), TCDTM (28.1 mg, 8.5 mol, 1.0 equiv.), ascorbic acid sodium salt (2.5 mg, $12.7 \mathrm{~mol}, 1.5$ equiv.) and $\mathrm{CuBr}$ (1.8 mg, 12.7 mol, 1.5 equiv.) were dissolved in $\mathrm{DMSO} / \mathrm{H}_{2} \mathrm{O}(\mathrm{v} / \mathrm{v}=1: 1)$ and stirred at room temperature under the protection of nitrogen. The reaction was monitored by HPLC. After the reaction was completed, the crude product was separated by semi-preparative HPLC. The product was freeze-dried to afford a light-red foam solid (15.2 mg, 46\% yield). HRMS (ESI) m/z: $[\mathrm{M}+3 \mathrm{H}]^{3+}$ calcd for $\mathrm{C}_{176} \mathrm{H}_{274} \mathrm{~N}_{64} \mathrm{O}_{35} \mathrm{~S}_{2}$, 1302.7021; found, 1303.0286. [M+4H] ${ }^{4+}$ calcd for $\mathrm{C}_{176} \mathrm{H}_{275} \mathrm{~N}_{64} \mathrm{O}_{35} \mathrm{~S}_{2}$, 977.2786; found, 977.5356. $[\mathrm{M}+5 \mathrm{H}]^{5+}$ calcd for $\mathrm{C}_{176} \mathrm{H}_{276} \mathrm{~N}_{64} \mathrm{O}_{35} \mathrm{~S}_{2}$, 782.0244; found, 782.2331. 


\section{Scheme s3}

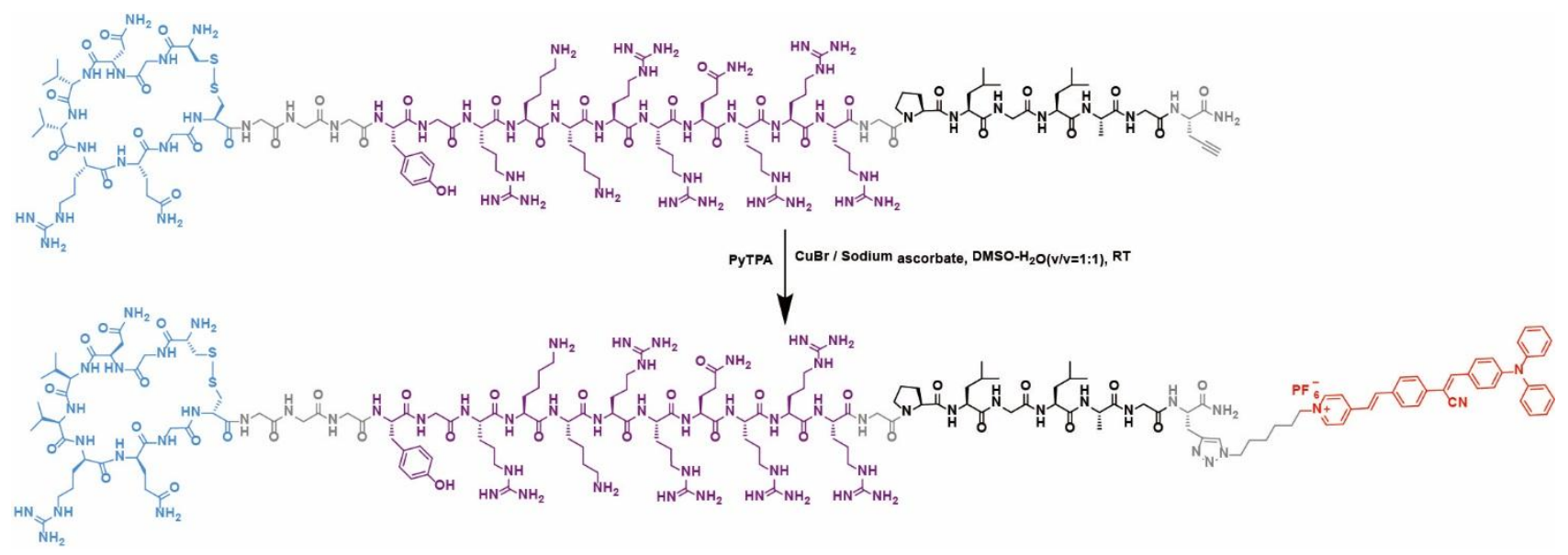

Scheme s3. The synthetic routes of $\mathrm{T}_{\mathrm{CL}} \mathrm{TMP}$. PyTPA (10.0 mg, $12.7 \mathrm{~mol}, 1.5$ equiv.), $\mathrm{T}_{\mathrm{CL}} \mathrm{TM}$ (28.1 mg, 8.5 mol, 1.0 equiv.), ascorbic acid sodium salt (2.5 mg, $12.7 \mathrm{~mol}, 1.5$ equiv.) and $\mathrm{CuBr}$ (1.8 mg, 12.7 mol, 1.5 equiv.) were dissolved in $\mathrm{DMSO} / \mathrm{H}_{2} \mathrm{O}(\mathrm{v} / \mathrm{v}=1: 1)$ and stirred at room temperature under the protection of nitrogen. The reaction was monitored by HPLC. After the reaction was completed, the crude product was separated by semi-preparative HPLC. The product was freeze-dried to afford a light-red foam solid (16.8 mg, 51\% yield). HRMS (ESI) m/z: $[\mathrm{M}+3 \mathrm{H}]^{3+}$ calcd for $\mathrm{C}_{176} \mathrm{H}_{274} \mathrm{~N}_{64} \mathrm{O}_{35} \mathrm{~S}_{2}$, 1302.7021; found, 1302.6928. $[\mathrm{M}+4 \mathrm{H}]^{4+}$ calcd for $\mathrm{C}_{176} \mathrm{H}_{275} \mathrm{~N}_{64} \mathrm{O}_{35} \mathrm{~S}_{2}$, 977.2786; found, 977.5303. $[\mathrm{M}+5 \mathrm{H}]^{5+}$ calcd for $\mathrm{C}_{176} \mathrm{H}_{276} \mathrm{~N}_{64} \mathrm{O}_{35} \mathrm{~S}_{2}, 782.0244$; found, 782.4282. $[\mathrm{M}+6 \mathrm{H}]^{6+}$ calcd for $\mathrm{C}_{176} \mathrm{H}_{277} \mathrm{~N}_{64} \mathrm{O}_{35} \mathrm{~S}_{2}$, 651.8550; found, 652.3696. 


\section{Scheme s4}

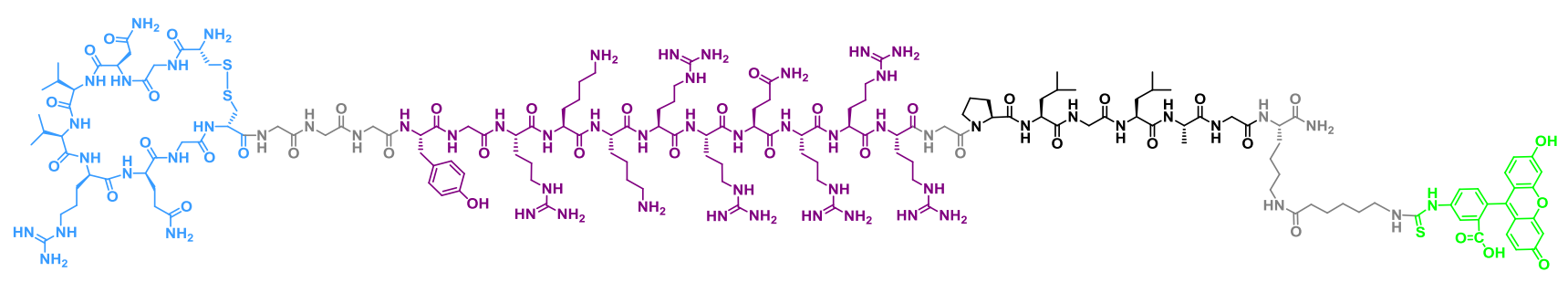

Scheme s4. The synthetic routes of $\mathrm{T}_{\mathrm{CD}} \mathrm{TMF}$. $\mathrm{T}_{\mathrm{CD}} \mathrm{TMF}$ was customized from GL Biochem Ltd. (Shanghai, China). HRMS (ESI) m/z: [FITC] ${ }^{+}$calcd for $\mathrm{C}_{21} \mathrm{H}_{12} \mathrm{NO}_{5} \mathrm{~S}, 390.0436$; found 390.0472 . $[\mathrm{M}+3 \mathrm{H}]^{3+}$ calcd for $\mathrm{C}_{164} \mathrm{H}_{266} \mathrm{~N}_{61} \mathrm{O}_{41} \mathrm{~S}_{3}, 1280.6589$; found, 1281.3415. $[\mathrm{M}+4 \mathrm{H}]^{4+}$ calcd for $\mathrm{C}_{164} \mathrm{H}_{267} \mathrm{~N}_{61} \mathrm{O}_{41} \mathrm{~S}_{3}$, 960.7461; found, 961.2607. $[\mathrm{M}+5 \mathrm{H}]^{5+}$ calcd for $\mathrm{C}_{164} \mathrm{H}_{268} \mathrm{~N}_{61} \mathrm{O}_{41} \mathrm{~S}_{3}, 768.7985$; found, 769.2098. 


\section{Scheme s5}

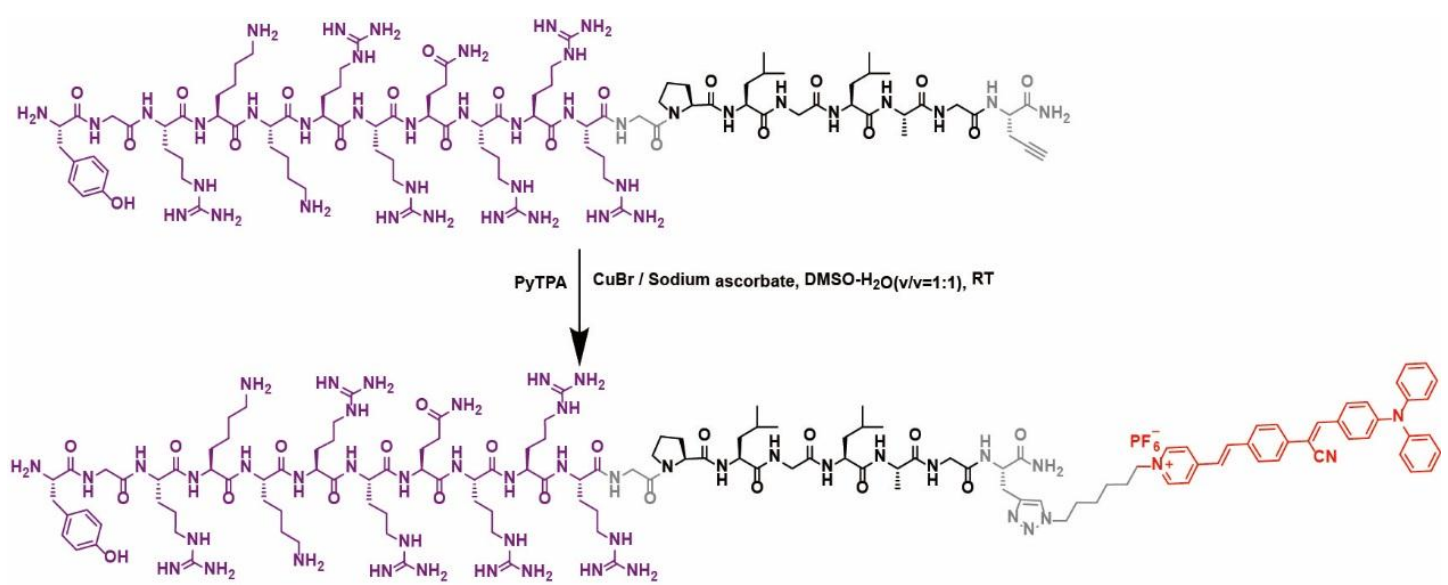

Scheme s5. The synthetic routes of TMP. PyTPA (10.0 mg, 12.7 mol, 1.5 equiv.), TM (18.9 mg, 8.5 mol, 1.0 equiv.), ascorbic acid sodium salt ( $2.5 \mathrm{mg}, 12.7 \mathrm{~mol}, 1.5$ equiv.) and $\mathrm{CuBr}(1.8 \mathrm{mg}, 12.7$ mol, 1.5 equiv.) were dissolved in $\mathrm{DMSO} / \mathrm{H}_{2} \mathrm{O}(\mathrm{v} / \mathrm{v}=1: 1)$ and stirred at room temperature under the protection of nitrogen. The reaction was monitored by HPLC. After the reaction was completed, the crude product was separated by semi-preparative HPLC. The product was freeze-dried to afford a light-red foam solid (20.6 mg, 86\% yield). HRMS (ESI) m/z: $[\mathrm{M}+2 \mathrm{H}]^{2+}$ calcd for $\mathrm{C}_{135} \mathrm{H}_{206} \mathrm{~N}_{47} \mathrm{O}_{21}$, 1410.8246; found, 1410.3508. $[\mathrm{M}+3 \mathrm{H}]^{3+}$ calcd for $\mathrm{C}_{135} \mathrm{H}_{207} \mathrm{~N}_{47} \mathrm{O}_{21}$, 940.8856; found, 940.9064 . $[\mathrm{M}+4 \mathrm{H}]^{4+}$ calcd for $\mathrm{C}_{135} \mathrm{H}_{208} \mathrm{~N}_{47} \mathrm{O}_{21}, 705.9162$; found, 705.9333. $[\mathrm{M}+5 \mathrm{H}]^{5+}$ calcd for $\mathrm{C}_{135} \mathrm{H}_{209} \mathrm{~N}_{47} \mathrm{O}_{21}$, 564.9345; found, 565.1573. 


\section{Scheme s6}

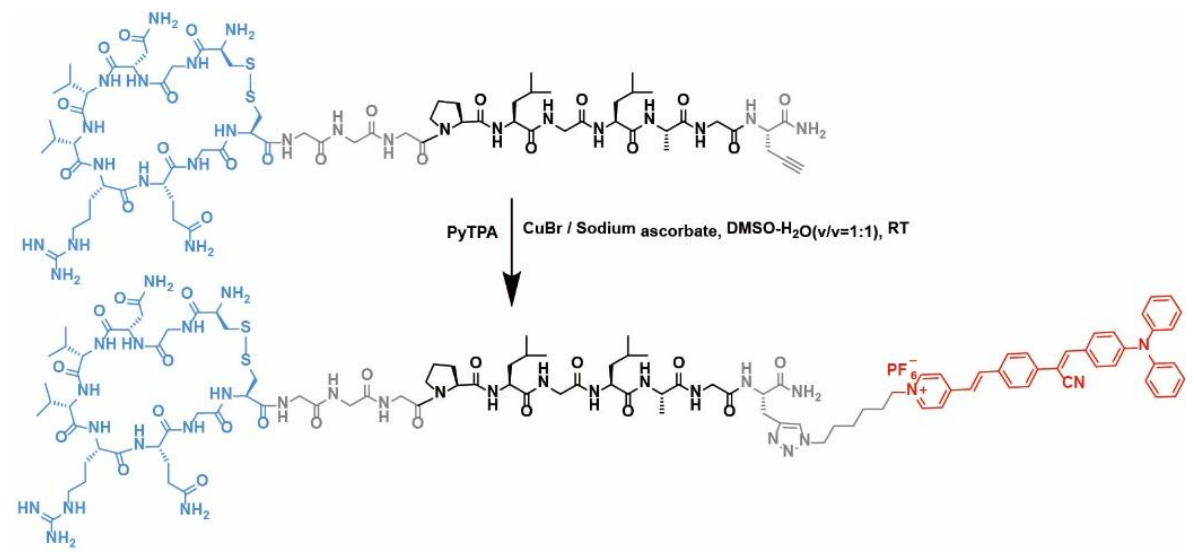

Scheme s6. The synthetic routes of $\mathrm{T}_{\mathrm{CD}} \mathrm{MP}$. PyTPA (10.0 mg, $12.7 \mu \mathrm{mol}, 1.5$ equiv.), $\mathrm{T}_{\mathrm{CD}} \mathrm{M}$ (14.5 $\mathrm{mg}, 8.5 \mu \mathrm{mol}, 1.0$ equiv.), ascorbic acid sodium salt (2.5 mg, $12.7 \mu \mathrm{mol}, 1.5$ equiv.) and $\mathrm{CuBr}(1.8$ $\mathrm{mg}, 12.7 \mu \mathrm{mol}, 1.5$ equiv.) were dissolved in $\mathrm{DMSO} / \mathrm{H}_{2} \mathrm{O}(\mathrm{v} / \mathrm{v}=1: 1)$ and stirred at room temperature under the protection of nitrogen. The reaction was monitored by HPLC. After the reaction was completed, the crude product was separated by semi-preparative HPLC. The product was freeze-dried to afford a light-red foam solid. HRMS (ESI) m/z: $[\mathrm{M}+2 \mathrm{H}]^{2+}$ calcd for $\mathrm{C}_{110} \mathrm{H}_{154} \mathrm{~N}_{31} \mathrm{O}_{21} \mathrm{~S}_{2}$, 1154.5686; found, 1154.85. $[\mathrm{M}+3 \mathrm{H}]^{3+}$ calcd for $\mathrm{C}_{110} \mathrm{H}_{155} \mathrm{~N}_{31} \mathrm{O}_{21} \mathrm{~S}_{2}, 770.0483$; found, 770.25. 


\section{Scheme s7}

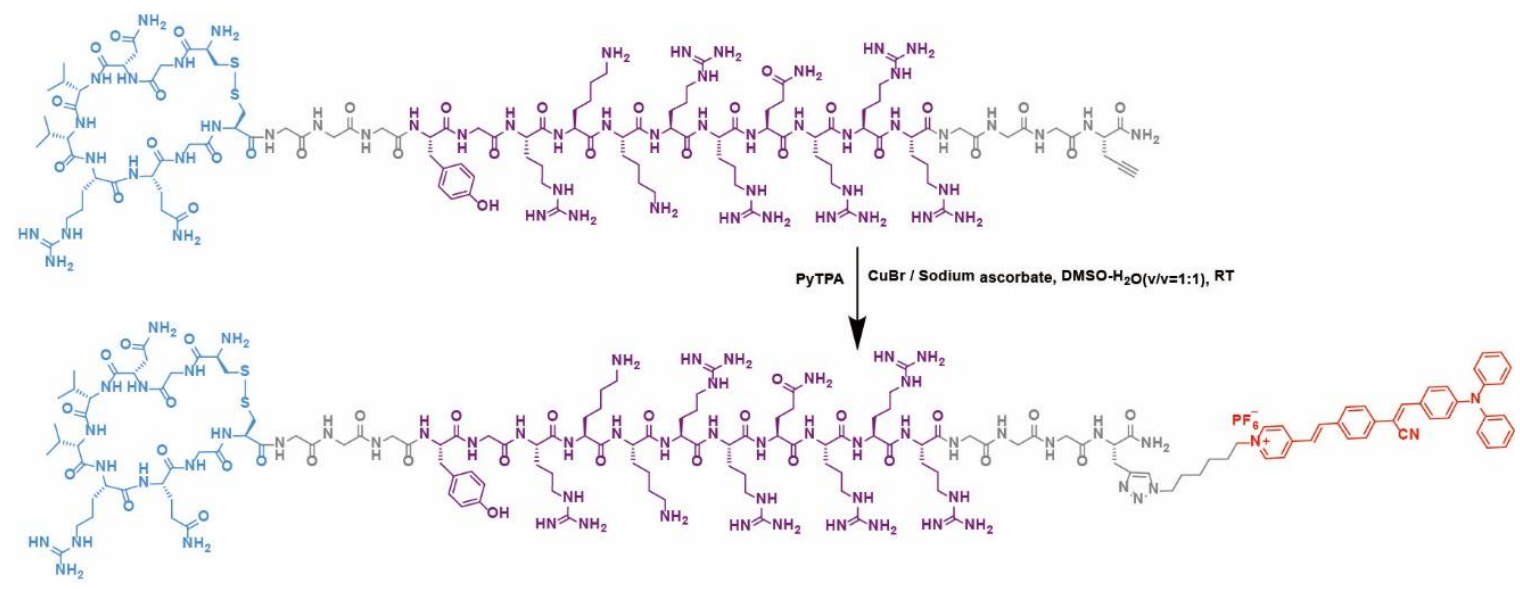

Scheme s7. The synthetic routes of $\mathrm{T}_{\mathrm{CD}} \mathrm{TP}$. PyTPA $\left(10.0 \mathrm{mg}, 12.7 \mu \mathrm{mol}, 1.5\right.$ equiv.), $\mathrm{T}_{\mathrm{CD}} \mathrm{T}(24.7 \mathrm{mg}$, $8.5 \mu \mathrm{mol}, 1.0$ equiv.), ascorbic acid sodium salt ( $2.5 \mathrm{mg}, 12.7 \mu \mathrm{mol}, 1.5$ equiv.) and $\mathrm{CuBr}(1.8 \mathrm{mg}$, $12.7 \mu \mathrm{mol}, 1.5$ equiv.) were dissolved in $\mathrm{DMSO} / \mathrm{H}_{2} \mathrm{O}(\mathrm{v} / \mathrm{v}=1: 1)$ and stirred at room temperature under the protection of nitrogen. The reaction was monitored by HPLC. After the reaction was completed, the crude product was separated by semi-preparative HPLC. The product was freeze-dried to afford a light-red foam solid. HRMS (ESI) m/z: $[\mathrm{M}+6 \mathrm{H}]^{6+}$ calcd for $\mathrm{C}_{176} \mathrm{H}_{277} \mathrm{~N}_{64} \mathrm{O}_{35} \mathrm{~S}_{2}$, 586.1453; found, 586.30. $[\mathrm{M}+7 \mathrm{H}]^{7+}$ calcd for $\mathrm{C}_{176} \mathrm{H}_{278} \mathrm{~N}_{64} \mathrm{O}_{35} \mathrm{~S}_{2}, 502.5542$; found, 502.80. $[\mathrm{M}+8 \mathrm{H}]^{8+}$ calcd for $\mathrm{C}_{176} \mathrm{H}_{279} \mathrm{~N}_{64} \mathrm{O}_{35} \mathrm{~S}_{2}$, 439.8609; found, 440.00. 
Figure s1

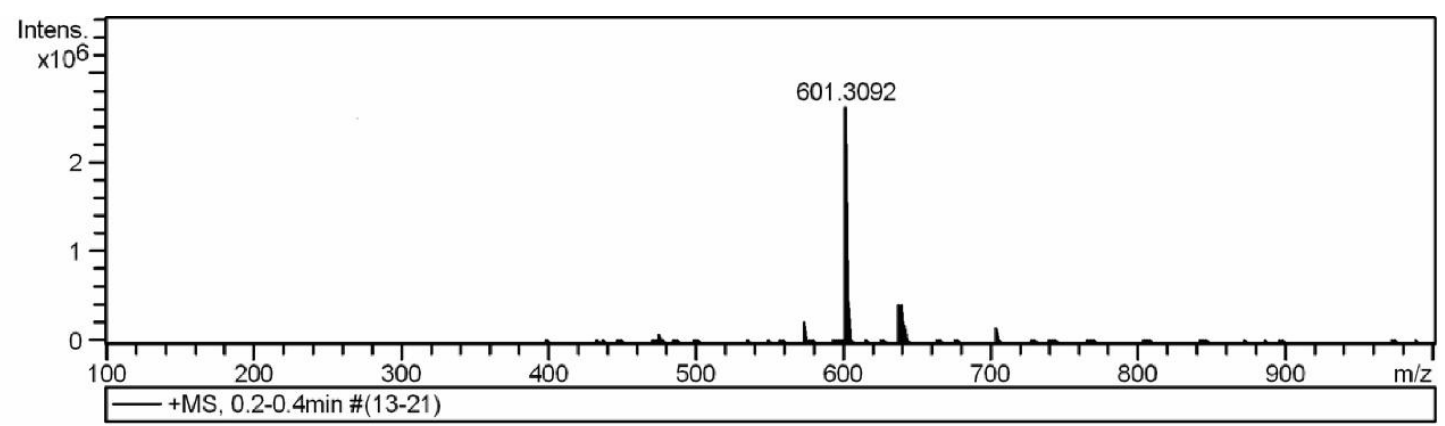

Figure s1. HRMS spectrum (MALDI-TOF) of compound PyTPA. 


\section{Figure s2}

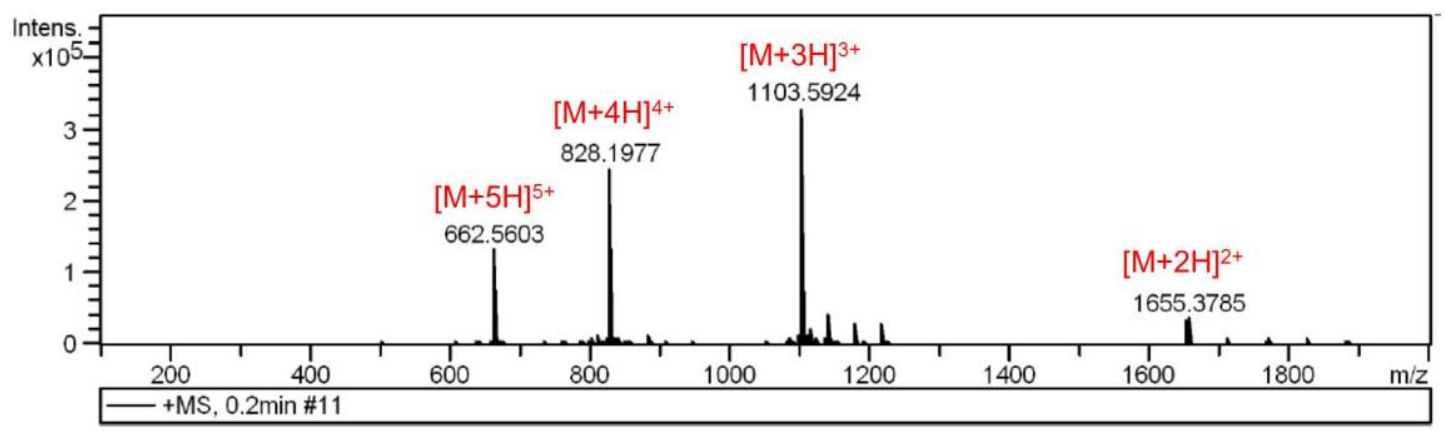

\begin{tabular}{rrrrrr}
$\#$ & $\mathbf{m} / \mathbf{z}$ & Res. & S/N & I & FWHM \\
\hline 1 & 662.5603 & 14283 & 277.0 & 132932 & 0.0464 \\
2 & 828.1977 & 15170 & 422.5 & 245003 & 0.0546 \\
3 & 1103.5924 & 16480 & 464.1 & 329277 & 0.0670 \\
4 & 1655.3785 & 14415 & 128.3 & 36872 & 0.1148
\end{tabular}

\begin{tabular}{|c|c|c|c|c|c|c|}
\hline $\mathrm{T}_{\mathrm{CD}} \mathrm{TM}$ & {$[\mathrm{M}]$} & {$[\mathrm{M}+\mathrm{H}]^{1+}$} & {$[\mathrm{M}+2 \mathrm{H}]^{2+}$} & {$[\mathrm{M}+3 \mathrm{H}]^{3+}$} & {$[\mathrm{M}+4 \mathrm{H}]^{4+}$} & {$[\mathrm{M}+5 \mathrm{H}]^{5+}$} \\
\hline $\mathrm{C}_{136} \mathrm{H}_{234} \mathrm{~N}_{58} \mathrm{O}_{35} \mathrm{~S}_{2}$ & 3303.7755 & 3304.7833 & 3305.7912 & 3306.7990 & 3307.8068 & 3308.8146 \\
\hline $\mathrm{m} / \mathrm{q}$ & & & 1652.8956 & 1102.2663 & 826.9517 & 661.7629 \\
\hline
\end{tabular}

Figure s2. HRMS spectrum (MALDI-TOF) of $\mathrm{T}_{\mathrm{CD}} \mathrm{TM}$. 


\section{Figure s3}

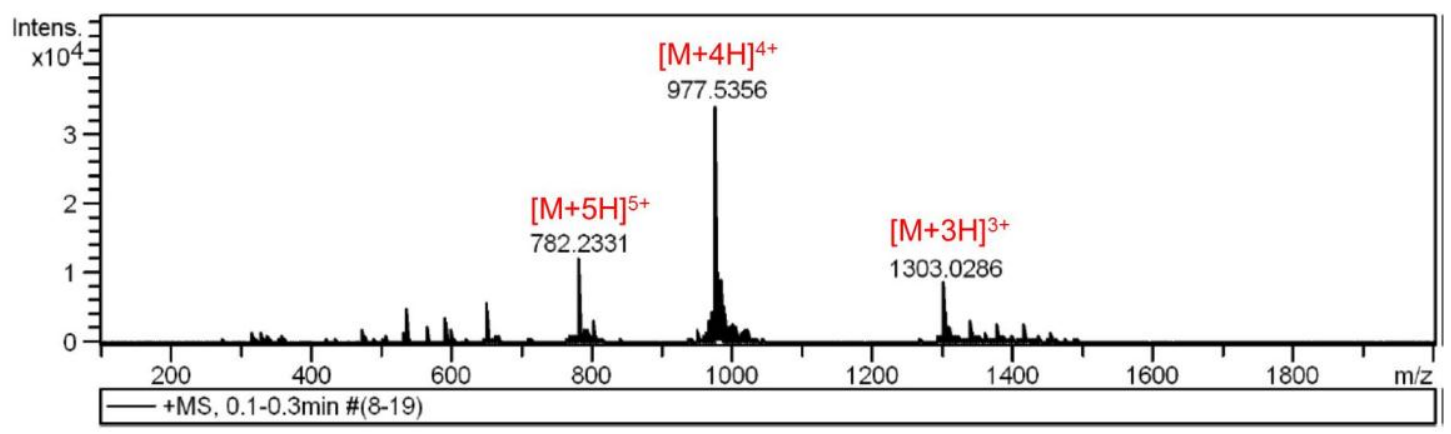

\begin{tabular}{rrrrrr}
$\#$ & $\mathbf{m} / \mathbf{z}$ & Res. & S/N & I & FWHM \\
\hline 1 & 782.2331 & 5788 & 77.6 & 11258 & 0.1352 \\
2 & 977.5356 & 5964 & 205.7 & 33597 & 0.1639 \\
3 & 1303.0286 & 8966 & 50.3 & 8483 & 0.1453
\end{tabular}

\begin{tabular}{|c|c|c|c|c|c|c|}
\hline $\mathrm{T}_{\mathrm{CD}} \mathrm{TMP}$ & {$[\mathrm{M}]$} & {$[\mathrm{M}+\mathrm{H}]^{1+}$} & {$[\mathrm{M}+2 \mathrm{H}]^{2+}$} & {$[\mathrm{M}+3 \mathrm{H}]^{3+}$} & {$[\mathrm{M}+4 \mathrm{H}]^{4+}$} & {$[\mathrm{M}+5 \mathrm{H}]^{5+}$} \\
\hline $\mathrm{C}_{176} \mathrm{H}_{271} \mathrm{~N}_{64} \mathrm{O}_{35} \mathrm{~S}_{2}$ & 3905.0829 & 3906.0907 & 3907.0986 & 3908.1064 & 3909.1142 & 3910.1220 \\
\hline $\mathrm{m} / \mathrm{q}$ & & & 1953.5493 & 1302.7021 & 977.2786 & 782.0244 \\
\hline
\end{tabular}

Figure s3. HRMS spectrum (MALDI-TOF) of T $\mathrm{CD}_{\mathrm{T}} \mathrm{TMP}$. 


\section{Figure s4}

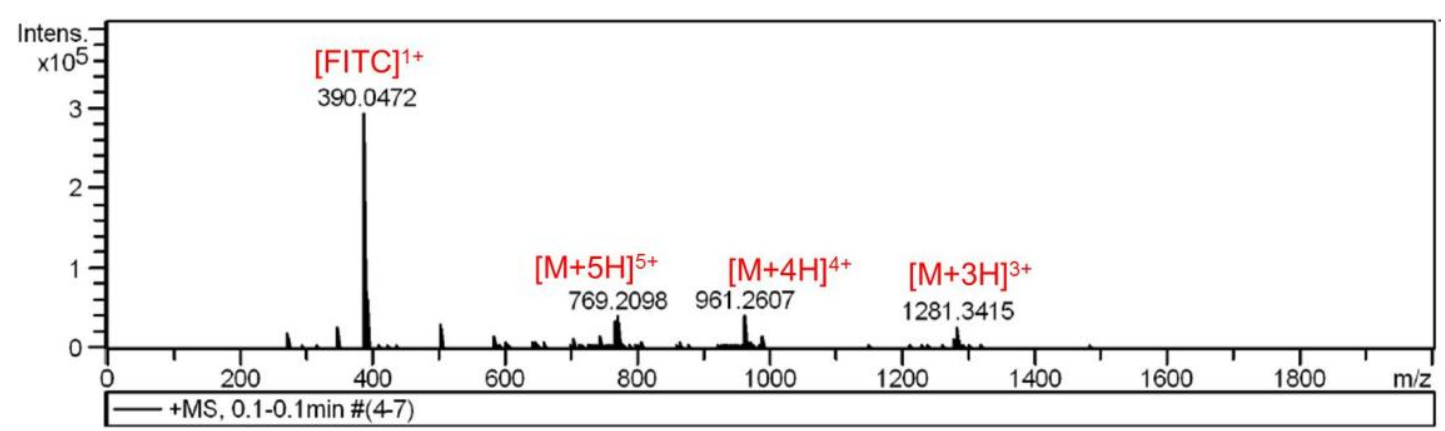

\begin{tabular}{rrrrrr}
$\#$ & $\mathbf{m} / \mathbf{z}$ & Res. & S/N & I & FWHM \\
\hline 1 & 390.0472 & 12993 & 919.7 & 294449 & 0.0300 \\
2 & 769.2098 & 11976 & 60.8 & 40007 & 0.0642 \\
3 & 961.2607 & 12051 & 71.6 & 41018 & 0.0798 \\
4 & 1281.3415 & 12582 & 71.1 & 28537 & 0.1018
\end{tabular}

\begin{tabular}{|c|c|c|c|c|c|c|}
\hline $\mathrm{T}_{\mathrm{CD}} \mathrm{TMF}$ & {$[\mathrm{M}]$} & {$[\mathrm{M}+\mathrm{H}]^{1+}$} & {$[\mathrm{M}+2 \mathrm{H}]^{2+}$} & {$[\mathrm{M}+3 \mathrm{H}]^{3+}$} & {$[\mathrm{M}+4 \mathrm{H}]^{4+}$} & {$[\mathrm{M}+5 \mathrm{H}]^{5+}$} \\
\hline $\mathrm{C}_{164} \mathrm{H}_{263} \mathrm{~N}_{61} \mathrm{O}_{41} \mathrm{~S}_{3}$ & 3838.9532 & 3839.9610 & 3840.9689 & 3841.9767 & 3842.9845 & 3843.9923 \\
$\mathrm{~m} / \mathrm{q}$ & & & 1920.4845 & 1280.6589 & 960.7461 & 768.7985 \\
\hline
\end{tabular}

Figure s4. HRMS spectrum (MALDI-TOF) of $\mathrm{T}_{\mathrm{CD}} \mathrm{TMF}$. 


\section{Figure s5}

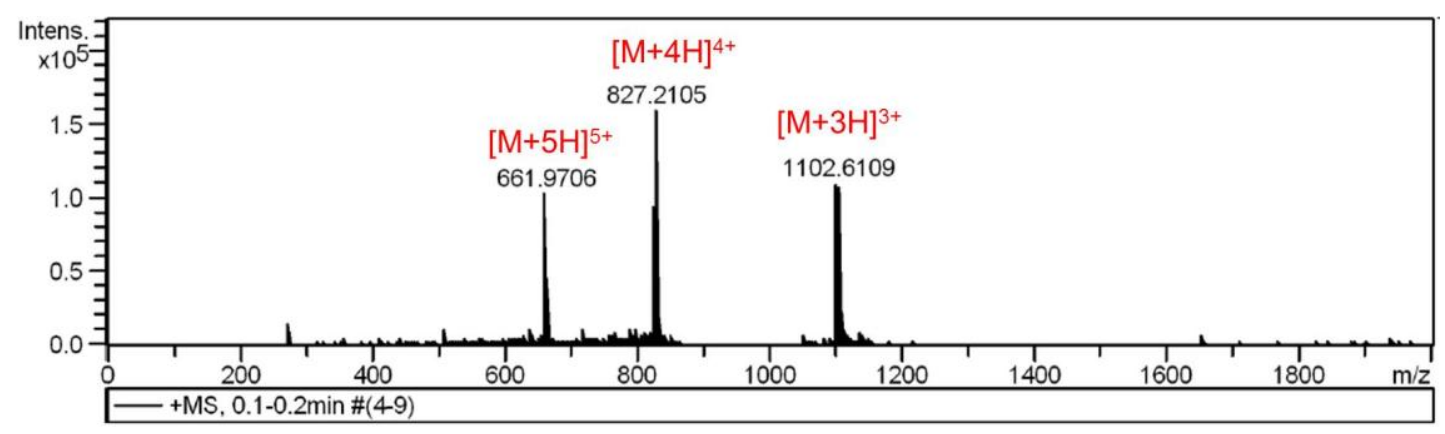

\begin{tabular}{rrrrrr}
$\#$ & $\mathbf{m} / \mathbf{z}$ & Res. & S/N & I & FWHM \\
\hline 1 & 661.9706 & 12810 & 145.3 & 101291 & 0.0517 \\
2 & 827.2105 & 13144 & 262.4 & 158625 & 0.0629 \\
3 & 1102.6109 & 13418 & 262.3 & 109730 & 0.0822
\end{tabular}

\begin{tabular}{|c|c|c|c|c|c|c|}
\hline $\mathrm{T}_{\mathrm{CL}} \mathrm{TM}$ & {$[\mathrm{M}]$} & {$[\mathrm{M}+\mathrm{H}]^{1+}$} & {$[\mathrm{M}+2 \mathrm{H}]^{2+}$} & {$[\mathrm{M}+3 \mathrm{H}]^{3+}$} & {$[\mathrm{M}+4 \mathrm{H}]^{4+}$} & {$[\mathrm{M}+5 \mathrm{H}]^{5+}$} \\
\hline $\mathrm{C}_{136} \mathrm{H}_{234} \mathrm{~N}_{58} \mathrm{O}_{35} \mathrm{~S}_{2}$ & 3303.7755 & 3304.7833 & 3305.7912 & 3306.7990 & 3307.8068 & 3308.8146 \\
\hline $\mathrm{m} / \mathrm{q}$ & & & 1652.8956 & 1102.2663 & 826.9517 & 661.7629 \\
\hline
\end{tabular}

Figure s5. HRMS spectrum (MALDI-TOF) of T $\mathrm{CL}_{\mathrm{T}} \mathrm{TM}$. 


\section{Figure s6}

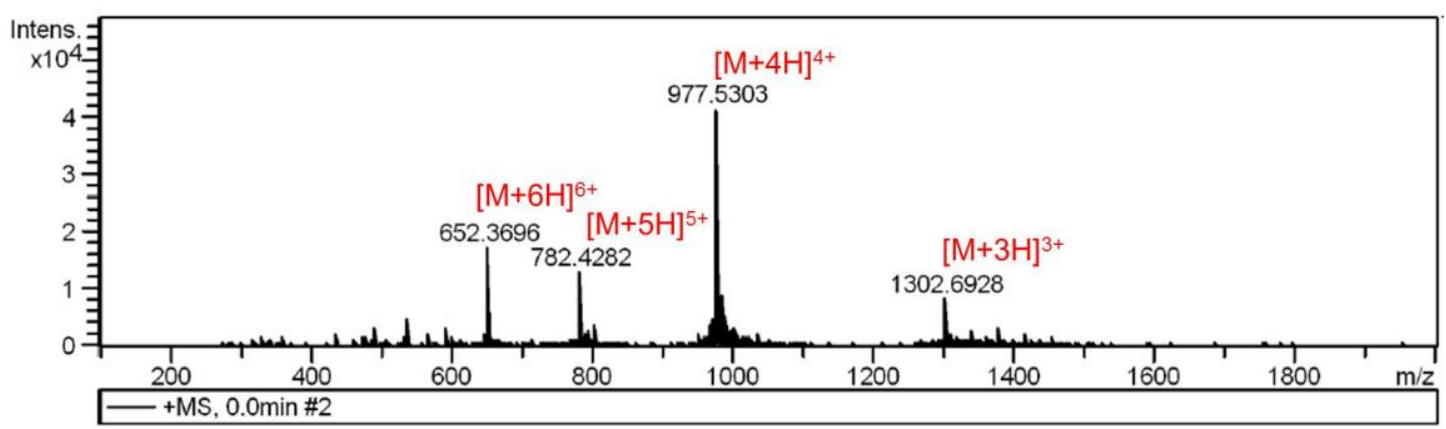

\begin{tabular}{rrrrrr}
$\#$ & $\mathbf{m} / \mathbf{z}$ & Res. & S/N & I & FWHM \\
\hline 1 & 652.3696 & 6631 & 41.4 & 17230 & 0.0984 \\
2 & 782.4282 & 6105 & 29.9 & 11711 & 0.1282 \\
3 & 977.5303 & 6355 & 90.6 & 37170 & 0.1538 \\
4 & 1302.6928 & 6575 & 14.3 & 5714 & 0.1981
\end{tabular}

\begin{tabular}{|c|c|c|c|c|c|c|}
\hline $\mathrm{T}_{\mathrm{CL}} \mathrm{TMP}$ & {$[\mathrm{M}]$} & {$[\mathrm{M}+2 \mathrm{H}]^{2+}$} & {$[\mathrm{M}+3 \mathrm{H}]^{3+}$} & {$[\mathrm{M}+4 \mathrm{H}]^{4+}$} & {$[\mathrm{M}+5 \mathrm{H}]^{5+}$} & {$[\mathrm{M}+6 \mathrm{H}]^{6+}$} \\
\hline $\mathrm{C}_{176} \mathrm{H}_{271} \mathrm{~N}_{64} \mathrm{O}_{35} \mathrm{~S}_{2}$ & 3905.0829 & 3907.0986 & 3908.1064 & 3909.1142 & 3910.1220 & 3911.1299 \\
\hline $\mathrm{m} / \mathrm{q}$ & & 1953.5493 & 1302.7021 & 977.2786 & 782.0244 & 651.8550 \\
\hline
\end{tabular}

Figure s6. HRMS spectrum (MALDI-TOF) of $\mathrm{T}_{\mathrm{CL}} \mathrm{TMP}$. 
Figure $\mathbf{s} 7$

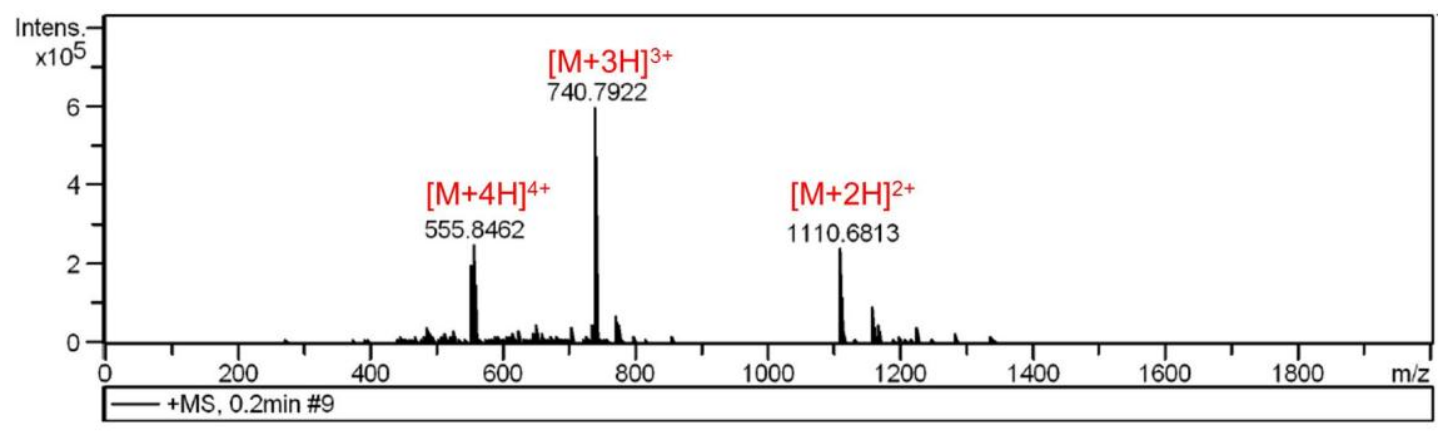

\begin{tabular}{rrrrrr}
$\#$ & $\mathbf{m} / \mathbf{z}$ & Res. & S/N & I & FWHM \\
\hline 1 & 555.8462 & 13097 & 218.2 & 249544 & 0.0424 \\
2 & 740.7922 & 15066 & 594.4 & 598031 & 0.0492 \\
3 & 1110.6813 & 14751 & 521.0 & 241753 & 0.0753
\end{tabular}

\begin{tabular}{|c|c|c|c|c|c|c|}
\hline $\mathrm{TM}$ & {$[\mathrm{M}]$} & {$[\mathrm{M}+\mathrm{H}]^{1+}$} & {$[\mathrm{M}+2 \mathrm{H}]^{2+}$} & {$[\mathrm{M}+3 \mathrm{H}]^{3+}$} & {$[\mathrm{M}+4 \mathrm{H}]^{4+}$} & {$[\mathrm{M}+5 \mathrm{H}]^{5+}$} \\
\hline $\mathrm{C}_{95} \mathrm{H}_{167} \mathrm{~N}_{41} \mathrm{O}_{21}$ & 2218.3260 & 2219.3338 & 2220.3417 & 2221.3495 & 2222.3495 & 2223.3651 \\
\hline $\mathrm{m} / \mathrm{q}$ & & & 1110.1709 & 740.4498 & 555.5893 & 444.6730 \\
\hline
\end{tabular}

Figure s7. HRMS spectrum (MALDI-TOF) of TM. 
Figure s8

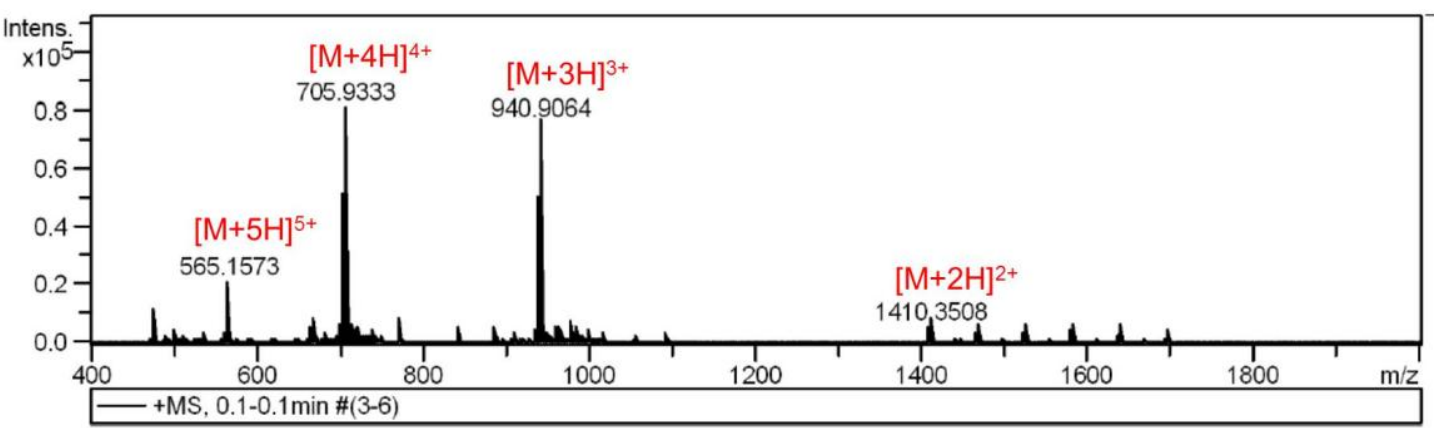

\begin{tabular}{rrrrrr}
$\#$ & $\mathbf{m} / \mathbf{z}$ & Res. & S/N & I & FWHM \\
\hline 1 & 565.1573 & 6743 & 79.7 & 21186 & 0.0838 \\
2 & 705.9333 & 6235 & 225.8 & 81040 & 0.1132 \\
3 & 940.9064 & 5985 & 193.6 & 75801 & 0.1572 \\
4 & 1410.3508 & 5137 & 24.2 & 4752 & 0.2746
\end{tabular}

\begin{tabular}{|c|c|c|c|c|c|c|}
\hline TMP & {$[M]$} & {$[M+H]^{1+}$} & {$[M+2 H]^{2+}$} & {$[M+3 H]^{3+}$} & {$[M+4 H]^{4+}$} & {$[M+5 H]^{5+}$} \\
\hline $\mathrm{C}_{135} \mathrm{H}_{204} \mathrm{~N}_{47} \mathrm{O}_{21}$ & 2819.6334 & 2820.6413 & 2821.6491 & 2822.6569 & 2823.6647 & 2824.6726 \\
\hline $\mathrm{m} / \mathrm{q}$ & & & 1410.8246 & 940.8856 & 705.9162 & 564.9345 \\
\hline
\end{tabular}

Figure s8. HRMS spectrum (MALDI-TOF) of TMP. 


\section{Figure s9}

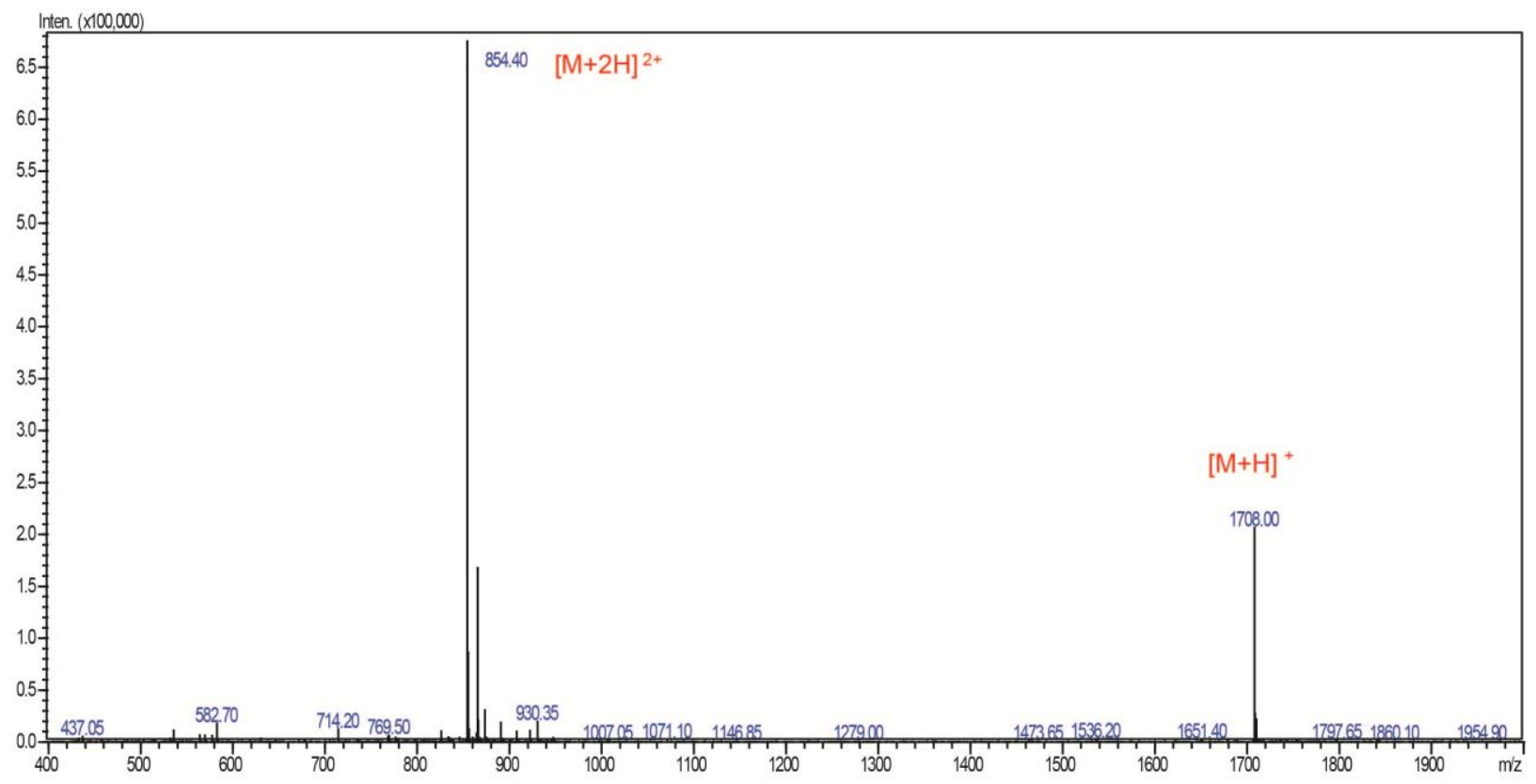

\begin{tabular}{|c|c|c|c|c|c|c|}
\hline TCDM & {$[\mathrm{M}]$} & {$[\mathrm{M}+\mathrm{H}]^{1+}$} & {$[\mathrm{M}+2 \mathrm{H}]^{2+}$} & {$[\mathrm{M}+3 \mathrm{H}]^{3+}$} & {$[\mathrm{M}+4 \mathrm{H}]^{4+}$} & {$[\mathrm{M}+5 \mathrm{H}]^{5+}$} \\
\hline $\mathrm{C}_{70} \mathrm{H}_{115} \mathrm{~N}_{25} \mathrm{O}_{21} \mathrm{~S}_{2}$ & 1705.8141 & 1706.8219 & 1707.8297 & 1708.8376 & 1709.8454 & 1710.8532 \\
\hline $\mathrm{m} / \mathrm{q}$ & & & 853.9148 & 569.6125 & 427.4614 & 342.1706 \\
\hline
\end{tabular}

Figure s9. HRMS spectrum (MALDI-TOF) of $\mathrm{T}_{\mathrm{CD}} \mathrm{M}$ 


\section{Figure s10}

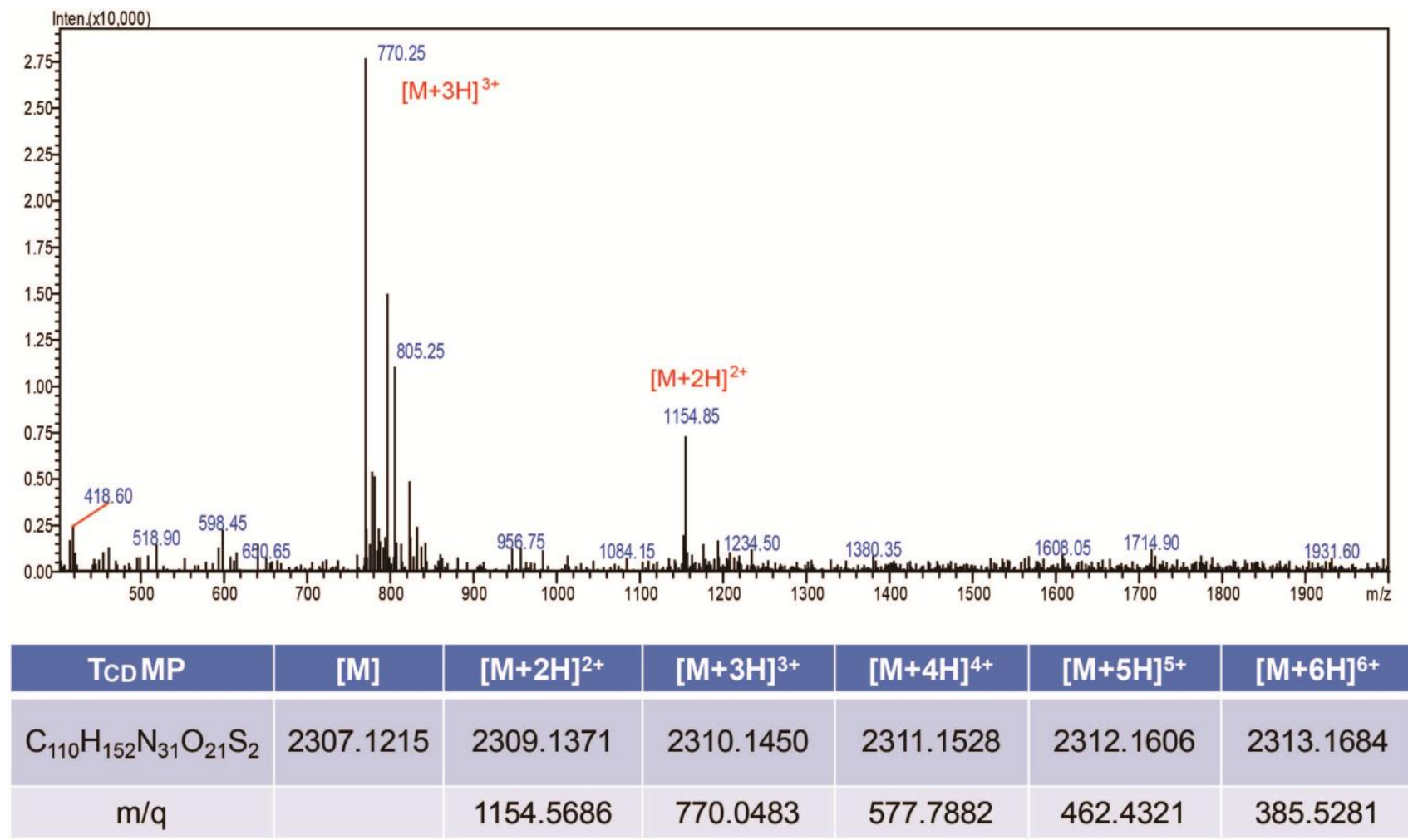

Figure s10. HRMS spectrum (MALDI-TOF) of $\mathrm{T}_{\mathrm{CD}} \mathrm{MP}$ 


\section{Figure s11}

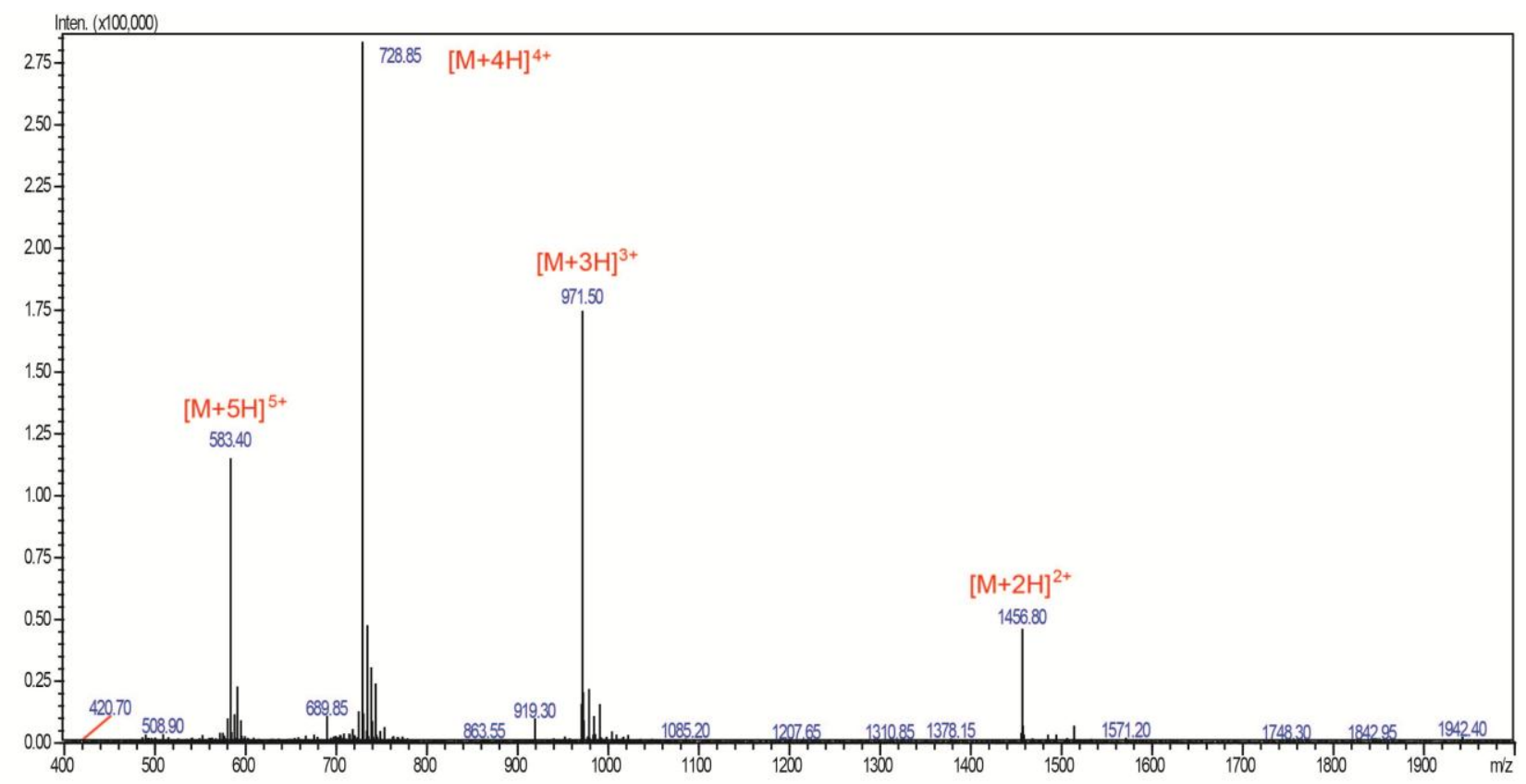

\begin{tabular}{|c|c|c|c|c|c|c|}
\hline $\mathrm{TCDT}$ & {$[\mathrm{M}]$} & {$[\mathrm{M}+\mathrm{H}]^{1+}$} & {$[\mathrm{M}+2 \mathrm{H}]^{2+}$} & {$[\mathrm{M}+3 \mathrm{H}]^{3+}$} & {$[\mathrm{M}+4 \mathrm{H}]^{4+}$} & {$[\mathrm{M}+5 \mathrm{H}]^{5+}$} \\
\hline $\mathrm{C}_{116} \mathrm{H}_{200} \mathrm{~N}_{54} \mathrm{O}_{31} \mathrm{~S}_{2}$ & 2909.5175 & 2910.5253 & 2911.5331 & 2912.5410 & 2913.5488 & 2914.5566 \\
\hline $\mathrm{m} / \mathrm{q}$ & & & 1455.7666 & 970.8470 & 728.3872 & 582.9113 \\
\hline
\end{tabular}

Figure s11. HRMS spectrum (MALDI-TOF) of $\mathrm{T}_{\mathrm{CD}} \mathrm{T}$. 


\section{Figure s12}

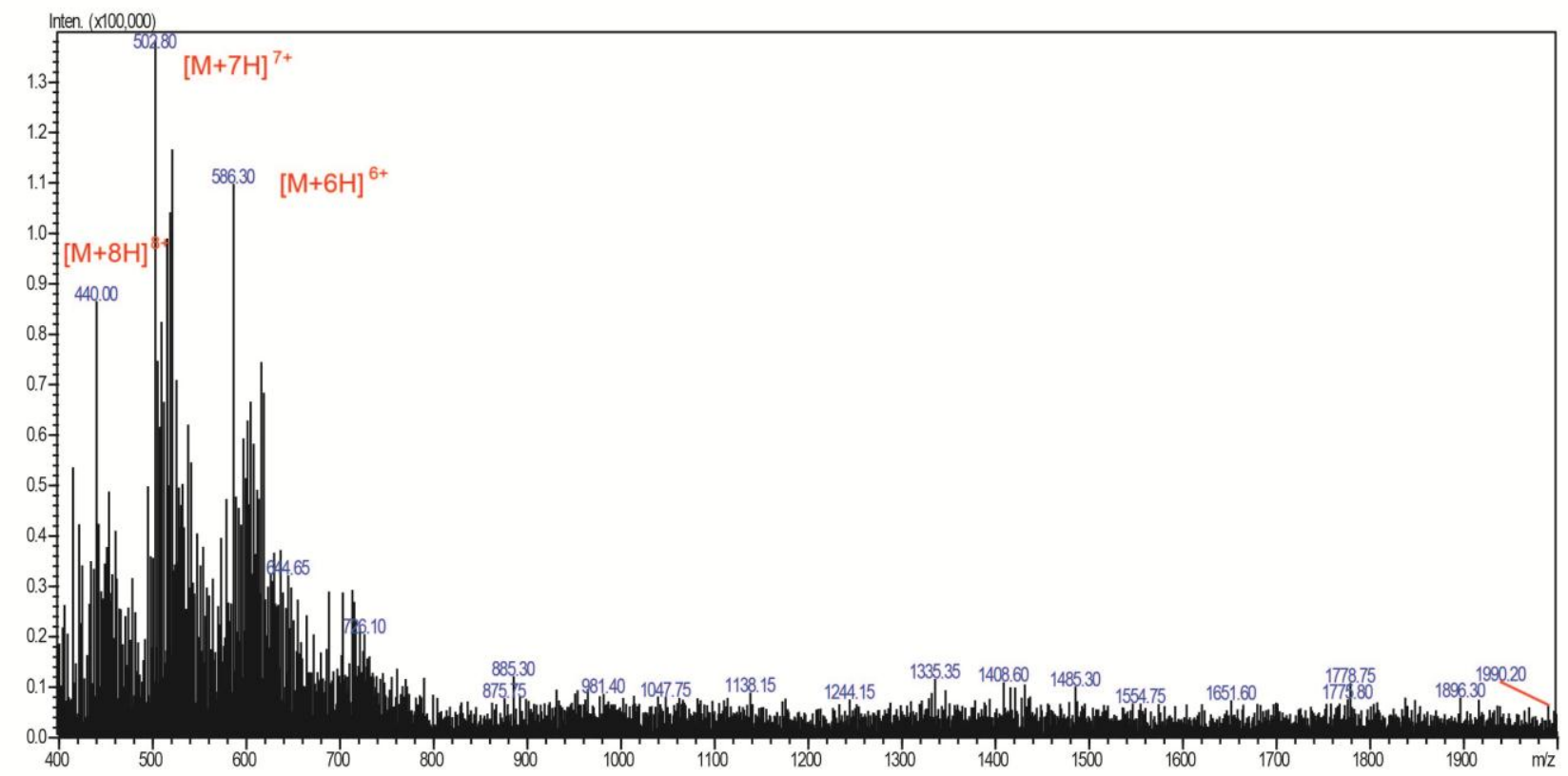

\begin{tabular}{|c|c|c|c|c|c|c|}
\hline TCDTP & {$[M]$} & {$[M+4 H]^{4+}$} & {$[M+5 H]^{5+}$} & {$[M+6 H]^{6+}$} & {$[M+7 H]^{7+}$} & {$[M+8 H]^{8+}$} \\
\hline $\mathrm{C}_{156} \mathrm{H}_{237} \mathrm{~N}_{60} \mathrm{O}_{31} \mathrm{~S}_{2}$ & 3510.8249 & 3514.8562 & 3515.8640 & 3513.8484 & 3514.8562 & 3515.8640 \\
\hline $\mathrm{m} / \mathrm{q}$ & & 878.7141 & 703.1728 & 586.1375 & 502.5464 & 439.8531 \\
\hline
\end{tabular}

Figure s12. HRMS spectrum (MALDI-TOF) of $\mathrm{T}_{\mathrm{CD}} \mathrm{TP}$. 
Figure s13

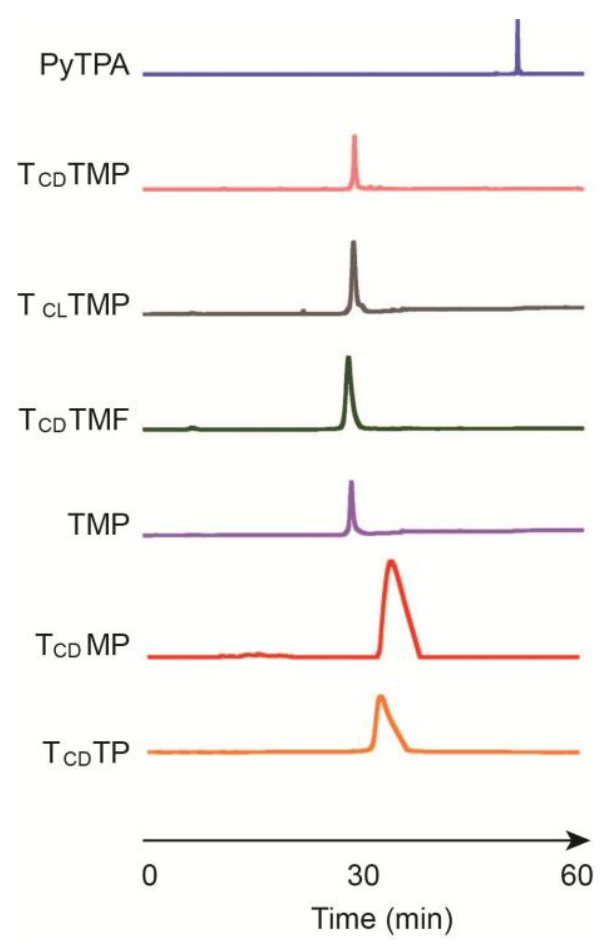

Figure s13. HPLC spectra of PyTPA, $\mathrm{T}_{\mathrm{CD}} \mathrm{TMP}, \mathrm{T}_{\mathrm{CL}} \mathrm{TMP}, \mathrm{T}_{\mathrm{CD}} \mathrm{TMF}, \mathrm{TMP}, \mathrm{T}_{\mathrm{CD}} \mathrm{MP}$ and $\mathrm{T}_{\mathrm{CD}} \mathrm{TP}$. 


\section{Figure s14}

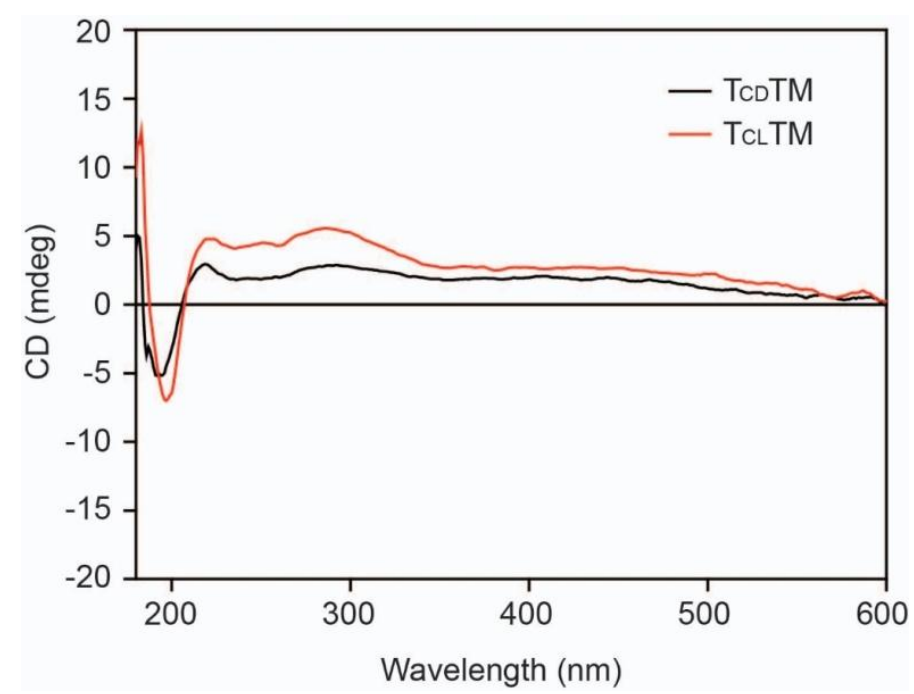

Figure s14. Circular dichroism (CD) spectra of the $\mathrm{T}_{\mathrm{CD}} \mathrm{TM}$ and $\mathrm{T}_{\mathrm{CL}} \mathrm{TM}$. Because containing different ratios of $\mathrm{L}$ and $\mathrm{D}$ amino acids, $\mathrm{T}_{\mathrm{CL}} \mathrm{TM}$ showed a stronger positive band from $210 \mathrm{~nm}$ to 350 $\mathrm{nm}$ and a weaker negative band from $190 \mathrm{~nm}$ to $210 \mathrm{~nm}$ than that of the $\mathrm{T}_{\mathrm{CD}} \mathrm{TM}$. 
Figure s15

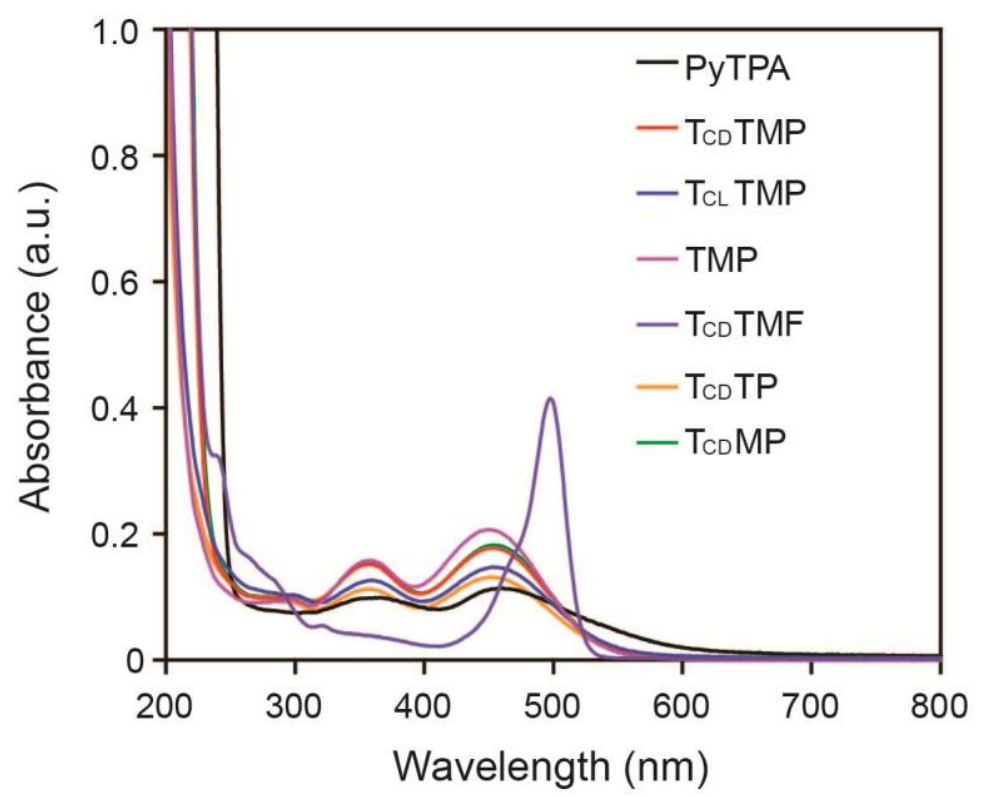

Figure s15. UV-vis spectra of $10 \mu \mathrm{M}$ PyTPA, $\mathrm{T}_{\mathrm{CD}} \mathrm{TMP}, \mathrm{T}_{\mathrm{CL}} \mathrm{TMP}, \mathrm{TMP}, \mathrm{T}_{\mathrm{CD}} \mathrm{TMF}, \mathrm{T}_{\mathrm{CD}} \mathrm{TP}$ and $\mathrm{T}_{\mathrm{CD}} \mathrm{MP}$ in DMSO/water mixture (v/v =1/99). 
Figure s16
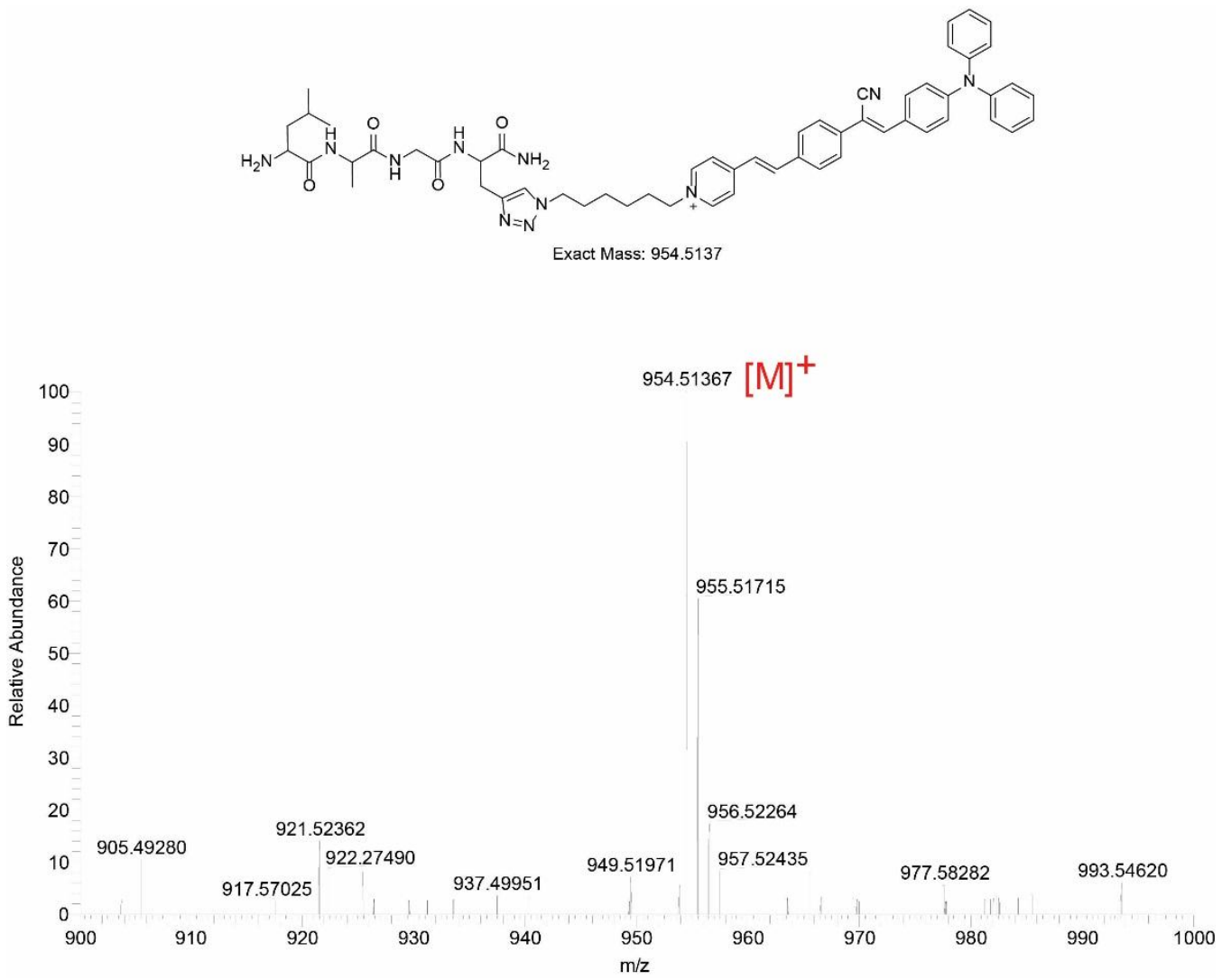

Figure s16. HRMS spectrum (MALDI-TOF) of $\mathrm{T}_{\mathrm{CD}} \mathrm{TMP}$ cleaved by MMP-2. 
Figure $\mathbf{s 1 7}$

a

TCDTMP

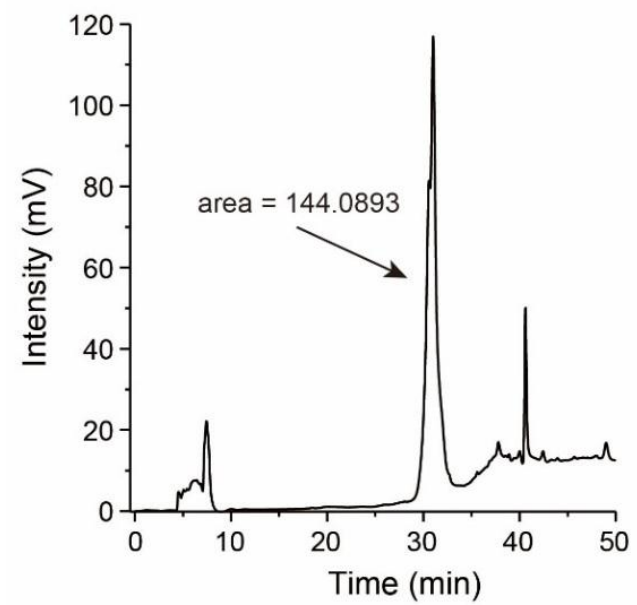

b
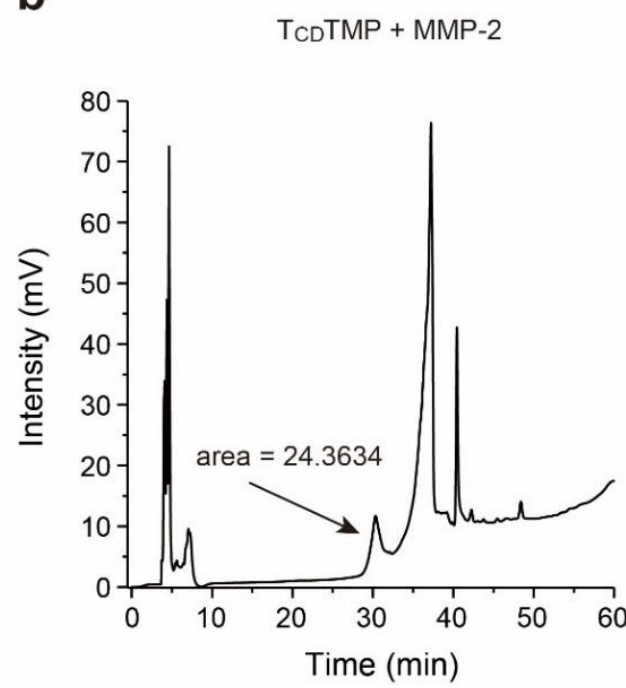

Figure s17. The HPLC spectrum of $\mathrm{T}_{\mathrm{CD}} \mathrm{TMP}$ was cleaved by MMP-2. The peak area of (a) $\mathrm{T}_{\mathrm{CD}} \mathrm{TMP}$ was 144.0893, which decreased to 24.3634 (b) after MMP-2 treatment. 
Figure s18

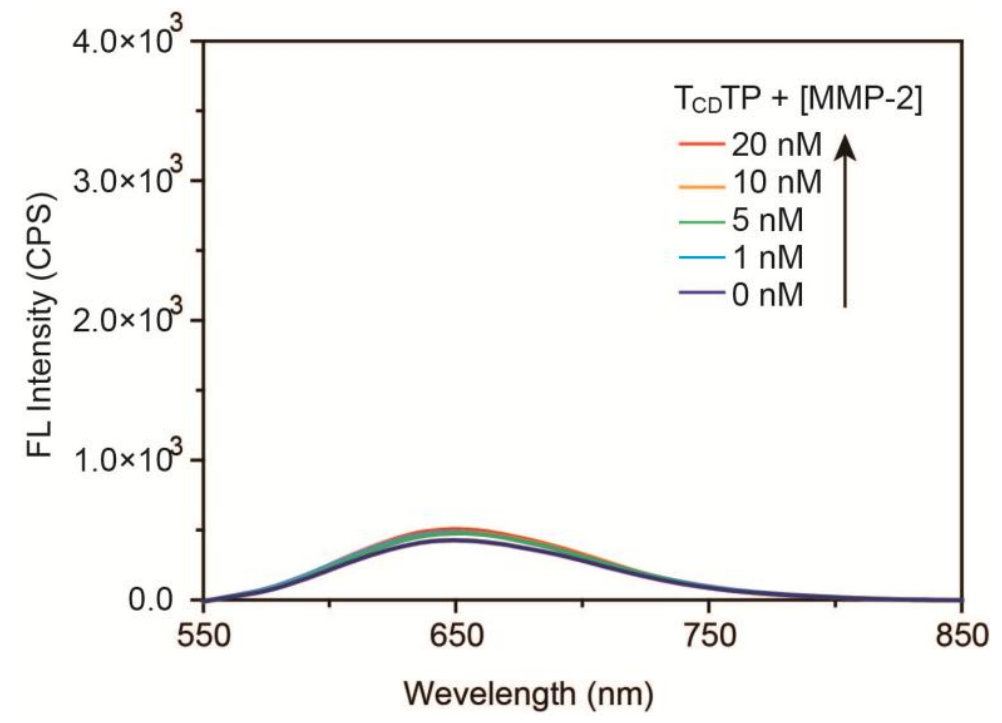

Figure s18. The fluorescence responses of $\mathrm{T}_{\mathrm{CD}} \mathrm{TP}(10 \mu \mathrm{M})$ with the addition of MMP-2 $(0 \mathrm{nM}-20$ $\mathrm{nM}$, incubation at $37^{\circ} \mathrm{C}$ for 60 minutes). 
Figure s19
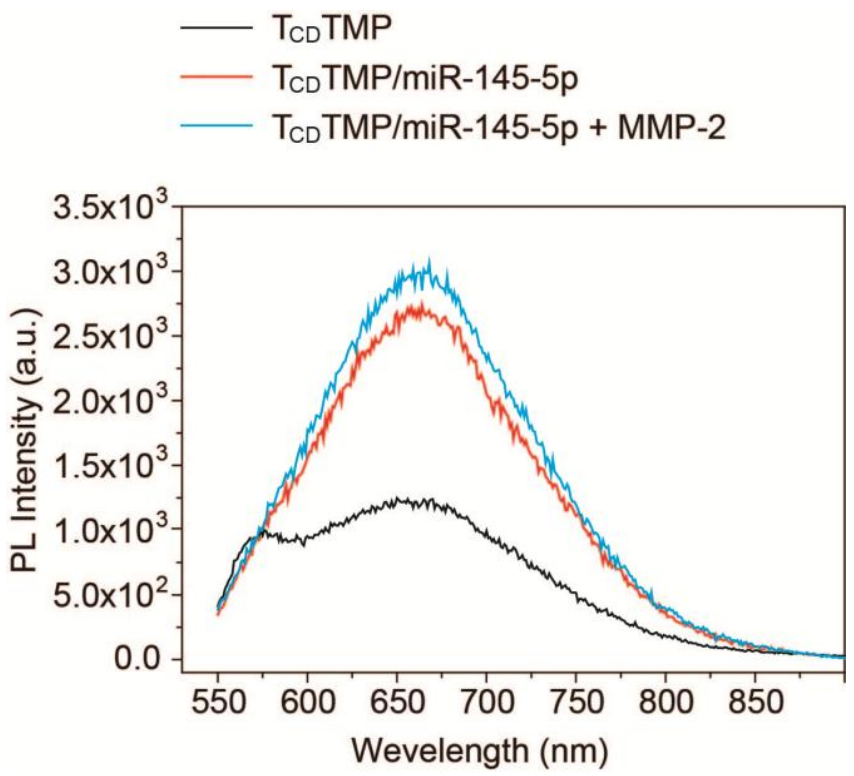

Figure s19. The fluorescence intensity of $\mathrm{T}_{\mathrm{CD}} \mathrm{TMP}(10 \mu \mathrm{M})$ increased significantly with the addition of miR-145-5p, and then increased slightly with the addition of MMP-2 (10 nM, incubation at $37^{\circ} \mathrm{C}$ for 60 minutes). 
Figure s20

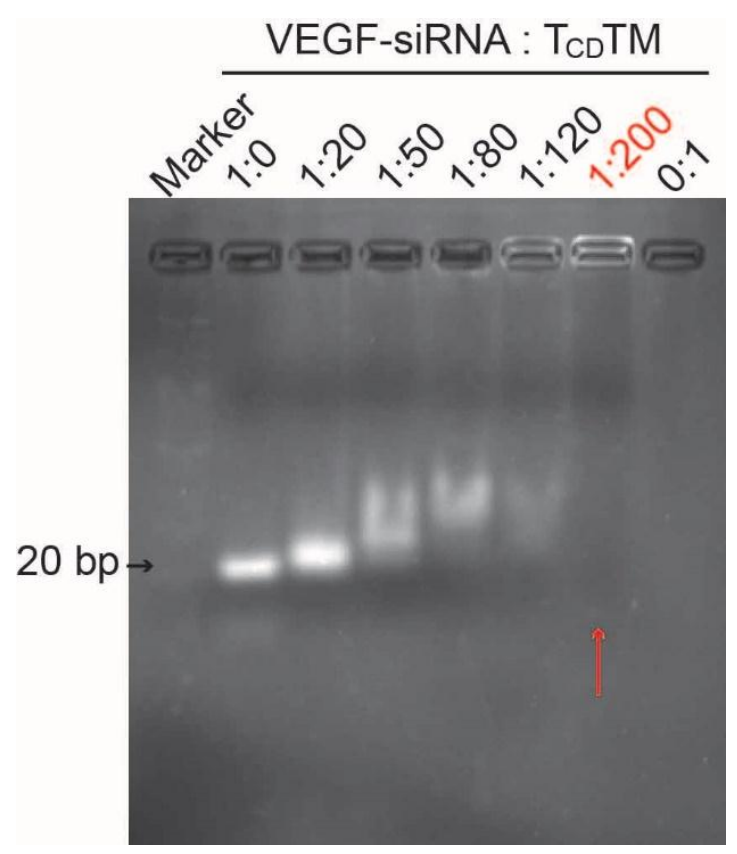

Figure s20. The capacity of $\mathrm{T}_{\mathrm{CD}} \mathrm{TM}$ loading VEGF-siRNA was analyzed by agarose gel electrophoresis in nuclease-free water at different molar ratios. The red arrow indicated the optimal load rate. 


\section{Figure s21}

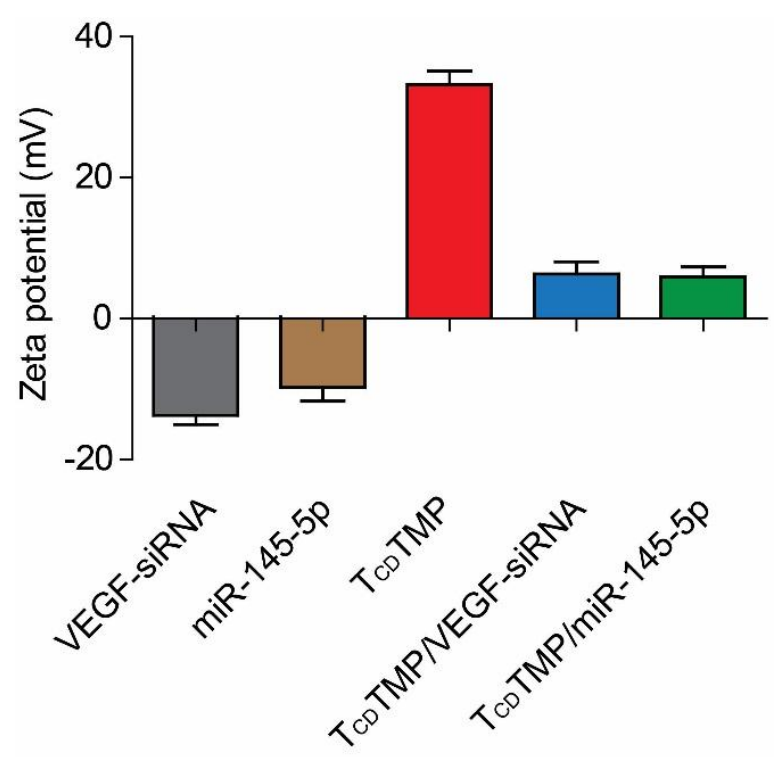

Figure s21. Zeta potentials of VEGF-siRNA, miR-145-5p, $\mathrm{T}_{\mathrm{CD}} \mathrm{TMP}, \mathrm{T}_{\mathrm{CD}} \mathrm{TMP} / \mathrm{VEGF}-\mathrm{siRNA}$ NPs $\left(\mathrm{T}_{\mathrm{CD}} \mathrm{TMP}:\right.$ VEGF-siRNA $\left.=60: 1\right)$ and $\mathrm{T}_{\mathrm{CD}} \mathrm{TMP} / \mathrm{miR}-145-5 \mathrm{p}$ NPs $\left(\mathrm{T}_{\mathrm{CD}} \mathrm{TMP}: \mathrm{miR}-145-5 \mathrm{p}=40: 1\right)$ in nuclease-free water. 
Figure s22

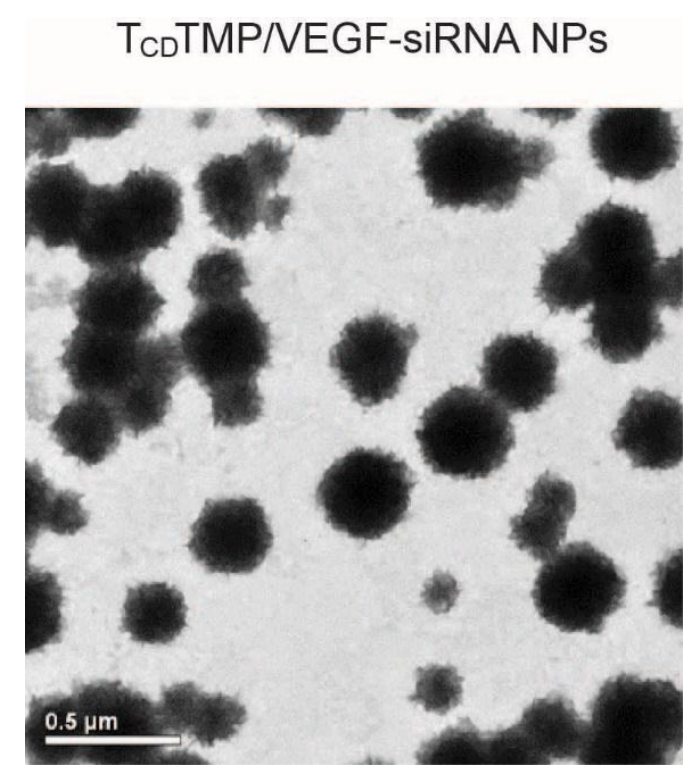

Figure s22. Transmission electron microscope (TEM) image of $\mathrm{T}_{\mathrm{CD}} \mathrm{TMP} / \mathrm{VEGF}-\mathrm{siRNA}$ NPs (the molar ratio of VEGF-siRNA to $\mathrm{T}_{\mathrm{CD}} \mathrm{TMP}$ was $\left.1: 60\right)$. Scale bars: $0.5 \mu \mathrm{m}$. 


\section{Figure s23}

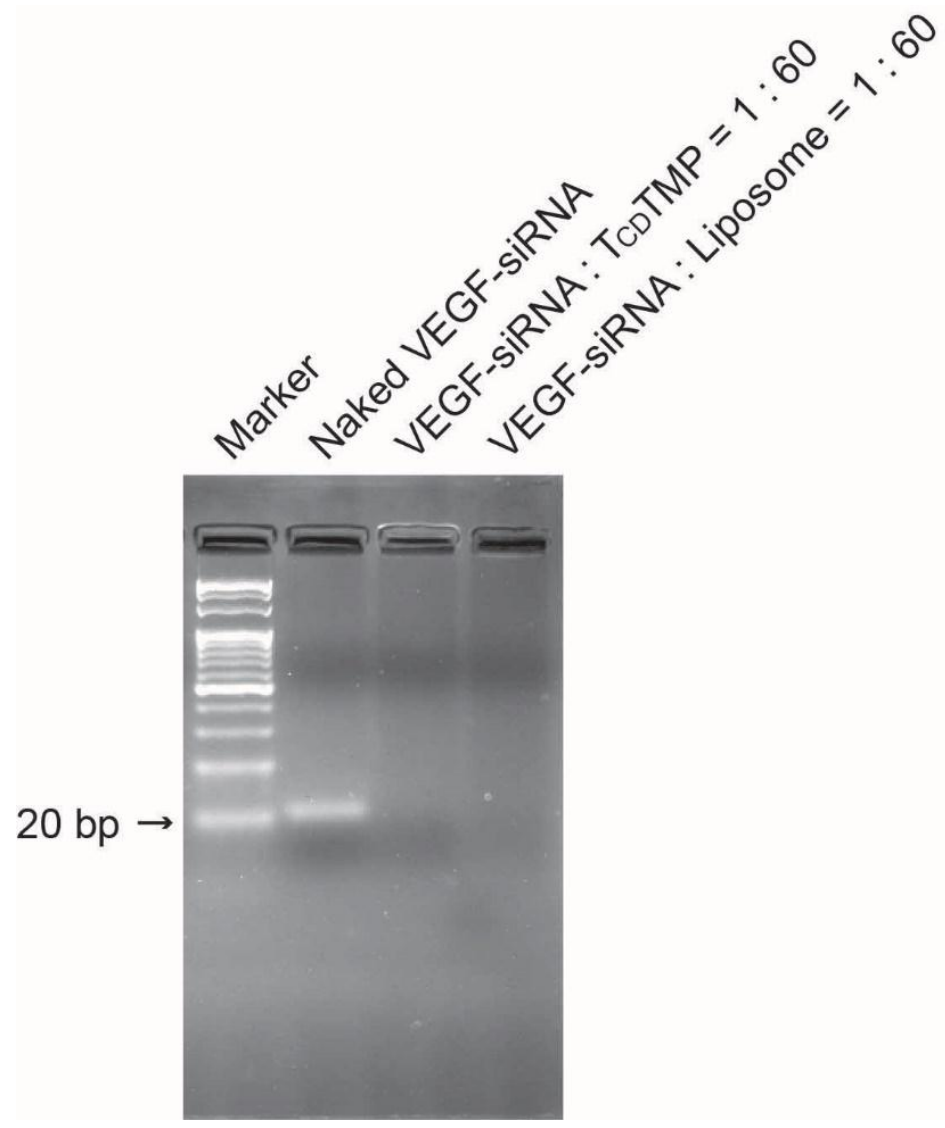

Figure s23. The VEGF-siRNA loading capacity of liposome and $\mathrm{T}_{\mathrm{CD}} \mathrm{TMP}$ was analyzed by agarose gel electrophoresis. 


\section{Figure s24}

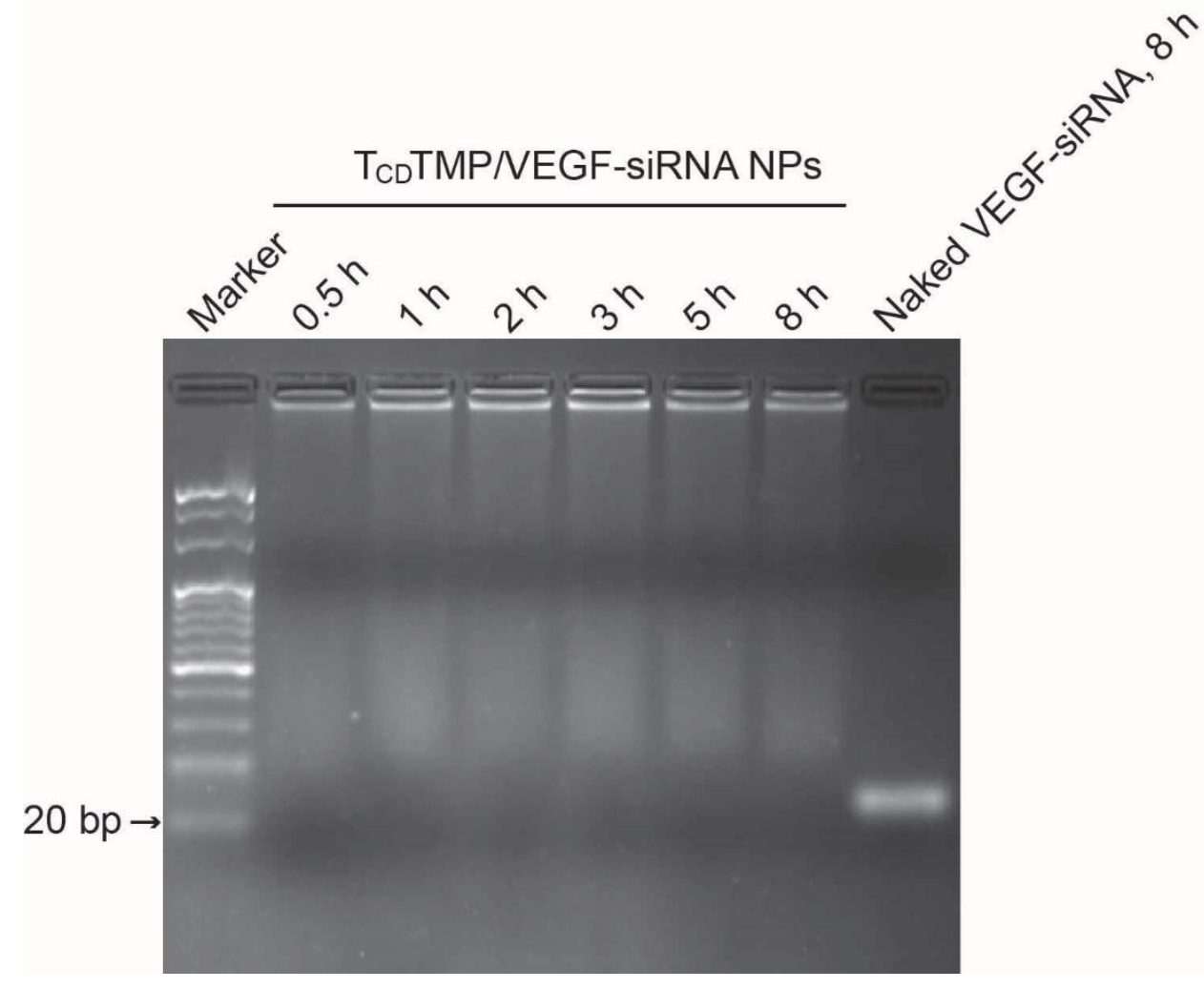

Figure s24. The stability of $\mathrm{T}_{\mathrm{CD}} \mathrm{TMP} / \mathrm{VEGF}-\mathrm{siRNA}$ NPs (the molar ratio of VEGF-siRNA to $\mathrm{T}_{\mathrm{CD}} \mathrm{TMP}$ was 1:60) was analyzed by agarose gel electrophoresis (room temperature) after standing in nuclease-free water containing $10 \%$ serum for $0.5,1,2,3,5,8 \mathrm{~h}$. 


\section{Figure s25}

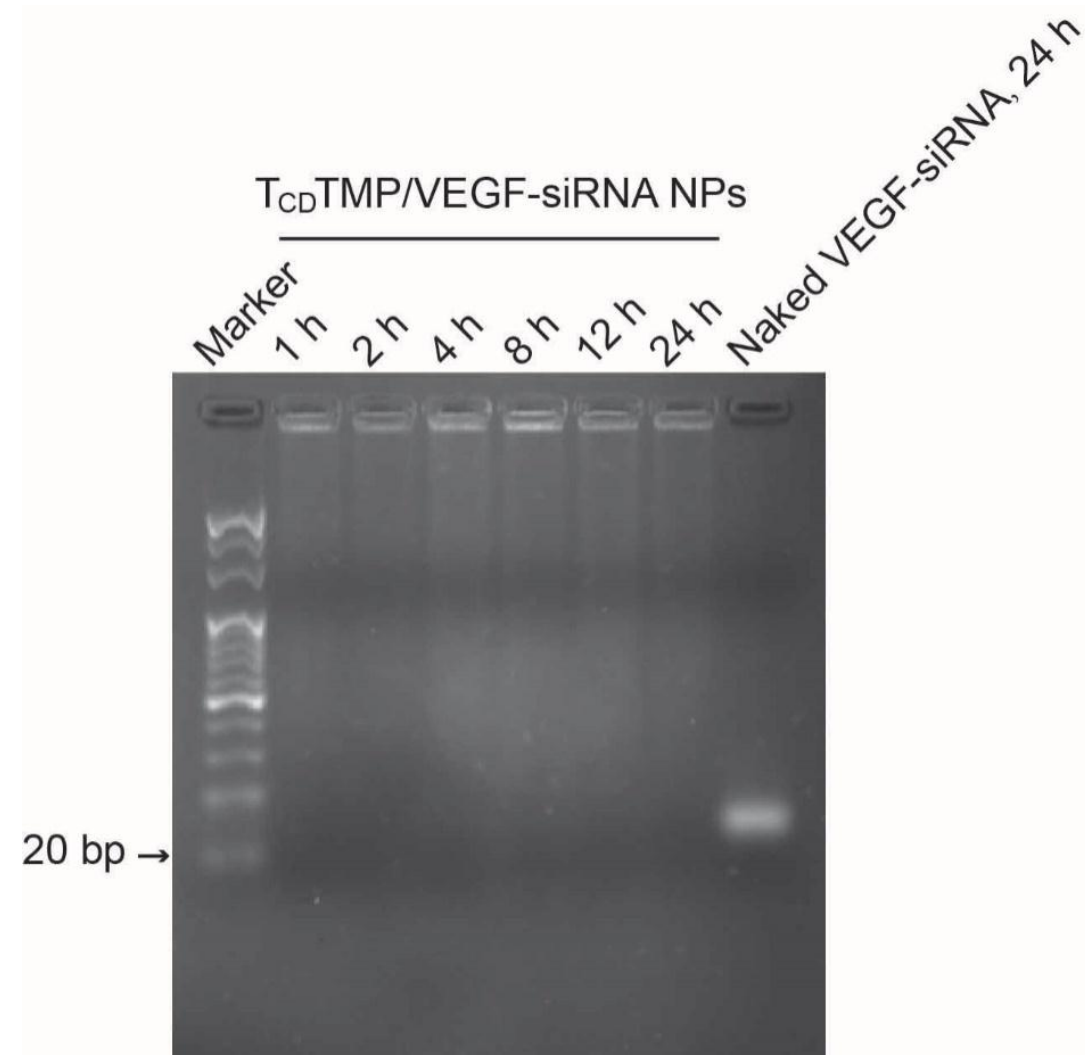

Figure s25. Agarose gel electrophoresis was used to analyze the stability of $\mathrm{T}_{\mathrm{CD}} \mathrm{TMP} / \mathrm{VEGF}-\mathrm{siRNA}$ NPs (the molar ratio of VEGF-siRNA to $\mathrm{T}_{\mathrm{CD}} \mathrm{TMP}$ was 1:60) after incubating in nuclease-free water at room temperature for $1,2,4,8,12,24$ hours. 
Figure s26
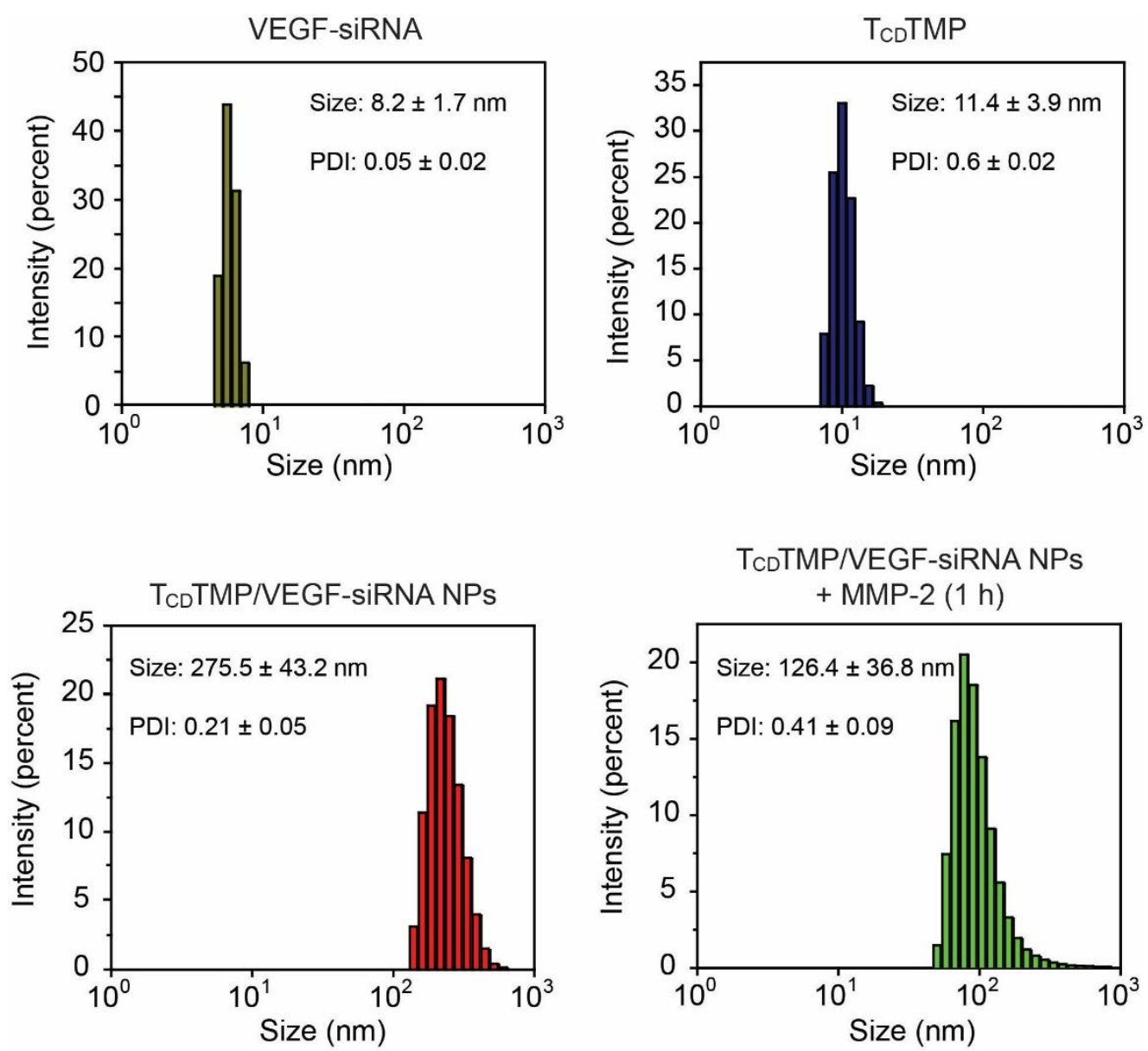

Figure s26. Diameter distribution of $\mathrm{T}_{\mathrm{CD}} \mathrm{TMP} / \mathrm{VEGF}-\mathrm{siRNA}$ NPs and $\mathrm{T}_{\mathrm{CD}} \mathrm{TMP} / \mathrm{VEGF}-\mathrm{siRNA}$ NPs +MMP-2 (MMP-2 was added to the prepared NPs after standing at $37{ }^{\circ} \mathrm{C}$ for 30 minutes, then the mixture was incubated at $37^{\circ} \mathrm{C}$ for 1 hour). 


\section{Figure s27}
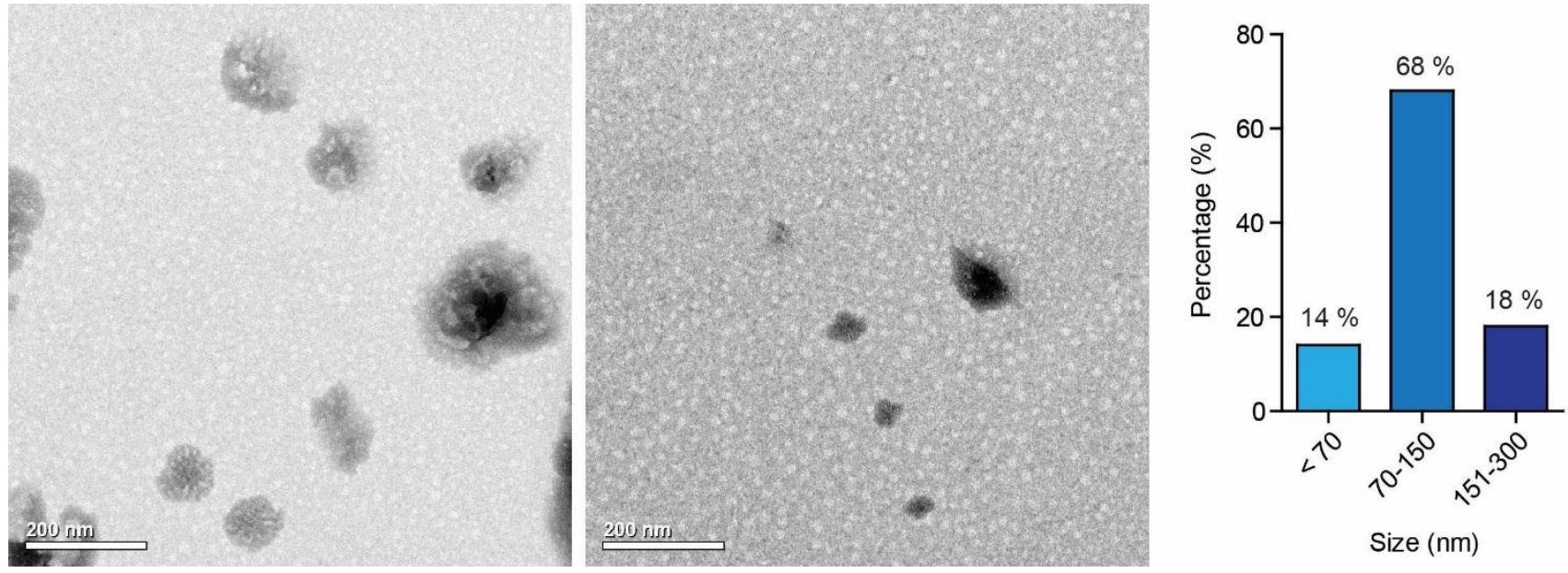

Figure s27. After $\mathrm{T}_{\mathrm{CD}} \mathrm{TMP} / \mathrm{VEGF}-\mathrm{siRNA}$ NPs were treated with MMP-2 for 1 hour, the morphology and size of NPs were observed by TEM. TEM shows representative images of three different sizes of NPs. Scale bars: $200 \mathrm{~nm}$ 


\section{Figure s28}

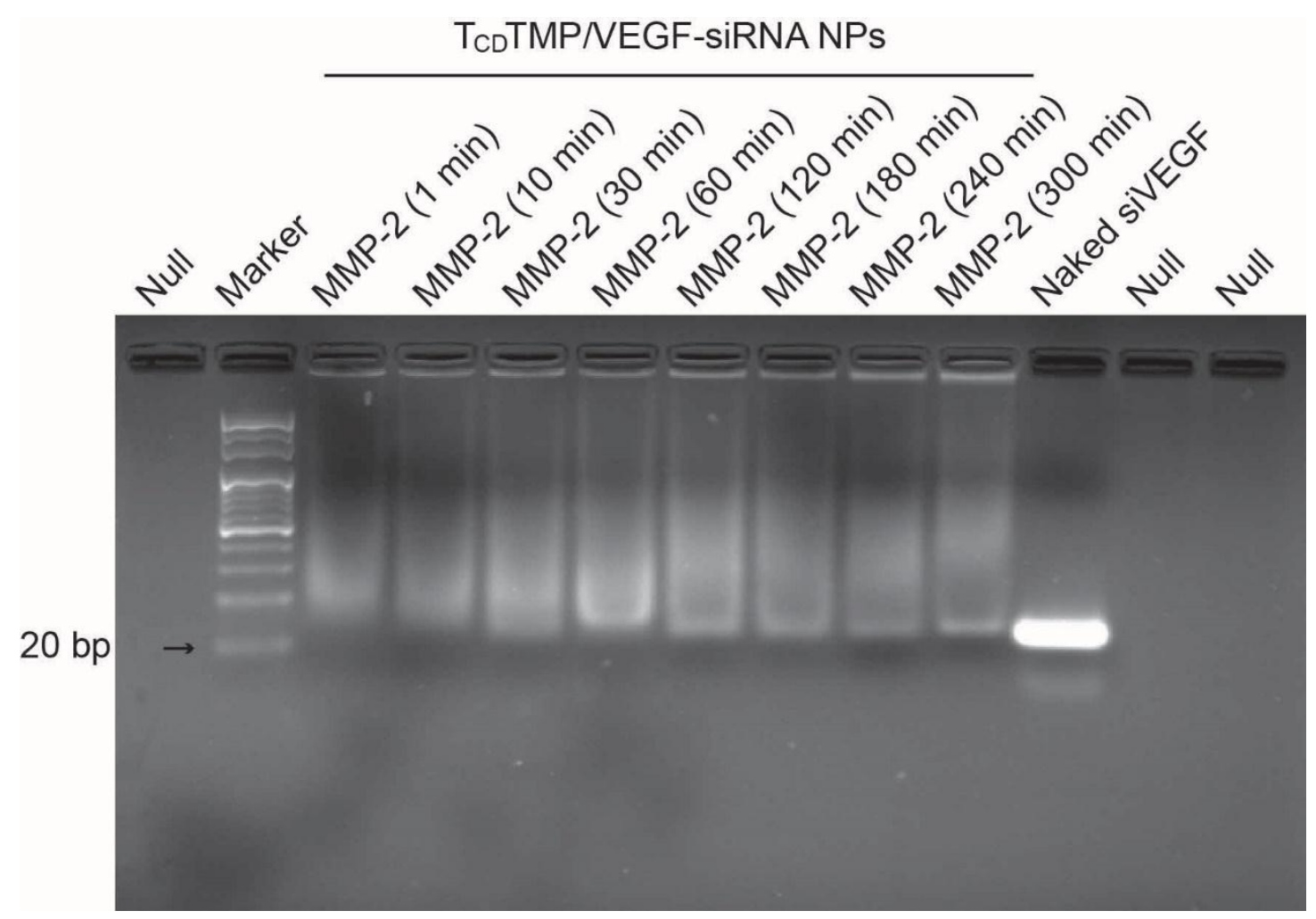

Figure s28. Agarose gel electrophoresis was performed to detect the release of VEGF-siRNA after treating $200 \mu \mathrm{l}$ of $\mathrm{T}_{\mathrm{CD}} \mathrm{TMP} / \mathrm{VEGF}$-siRNA NPs (the molar ratio of VEGF-siRNA to $\mathrm{T}_{\mathrm{CD}} \mathrm{TMP}$ was 1:60) with activated MMP-2 (20 nM) for different time. 
Figure s29
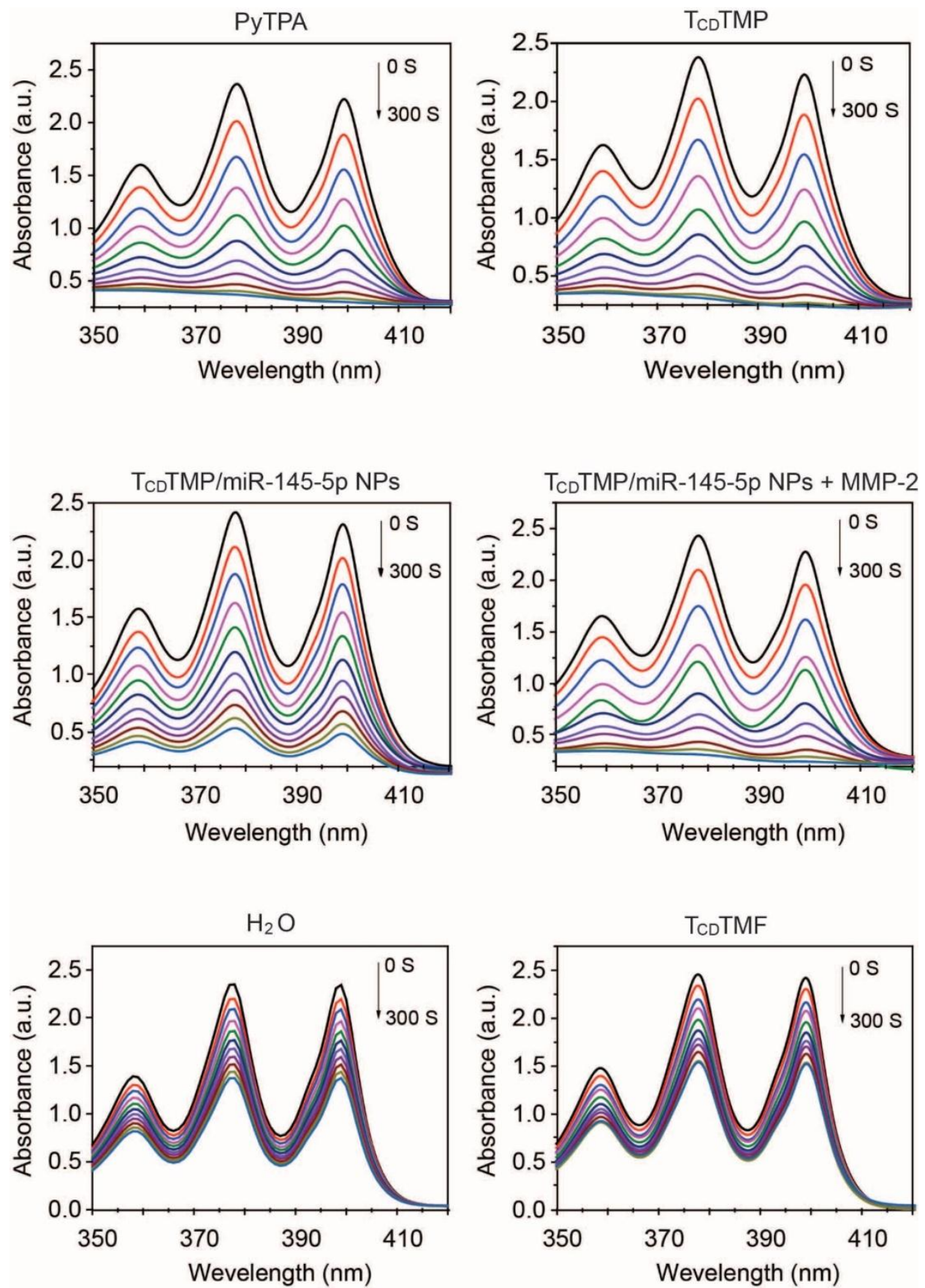

Figure s29. UV-vis spectrum of the ABDA (ROS indicator) after mixed with PyTPA, $\mathrm{T}_{\mathrm{CD}} \mathrm{TMP}$, $\mathrm{T}_{\mathrm{CD}} \mathrm{TMP} / \mathrm{miR}-145-5 p$ NPs, $\mathrm{T}_{\mathrm{CD}} \mathrm{TMP} / \mathrm{miR}-145-5 \mathrm{p}$ NPs $+\mathrm{MMP}-2, \mathrm{H}_{2} \mathrm{O}$ and $\mathrm{T}_{\mathrm{CD}} \mathrm{TMF}$ upon light irradiation (white light, $20 \mathrm{~mW} / \mathrm{cm}^{2}$ ), respectively. 
Figure s30

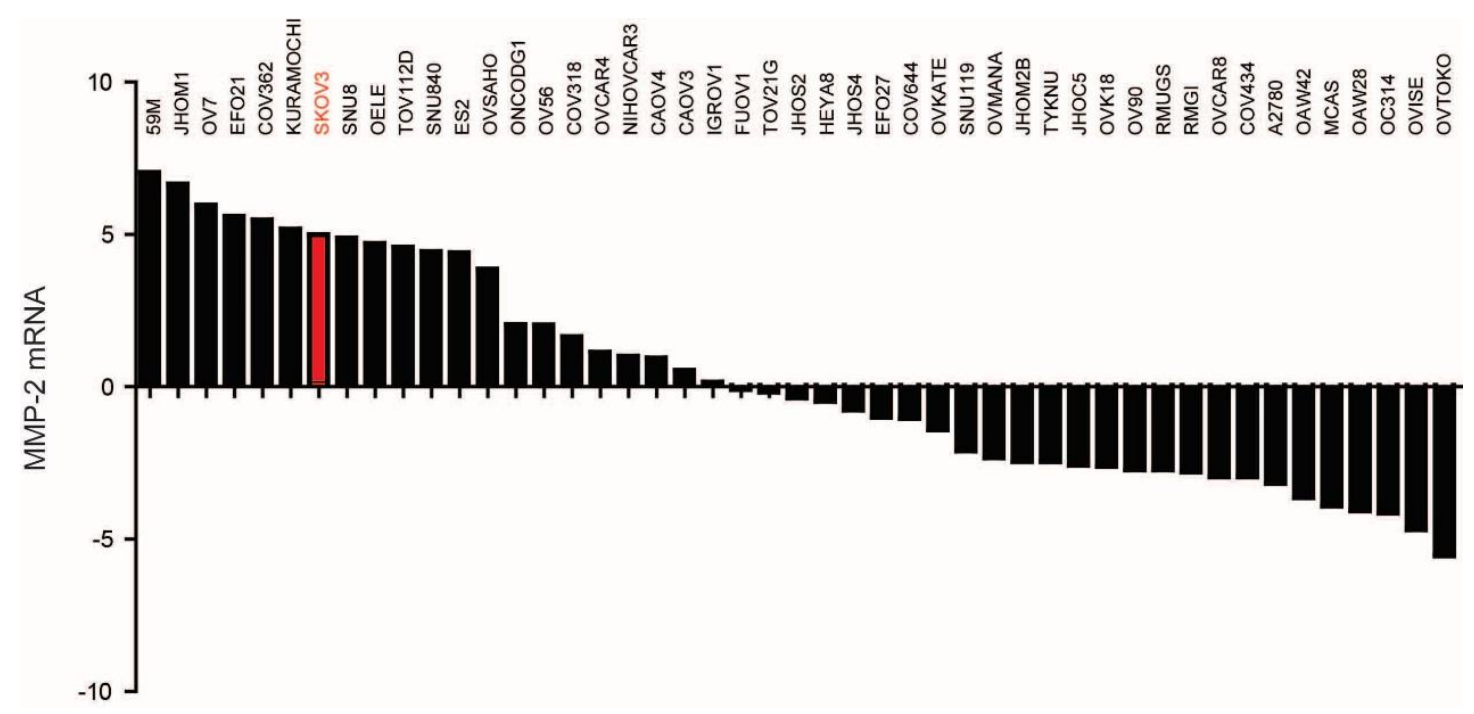

Figure s30. Expression of MMP-2 mRNA in different ovarian cancer cell lines. Data from Cancer Cell Line Encyclopedia (https://portals.broadinstitute.org/ccle/about). 


\section{Figure s31}

a

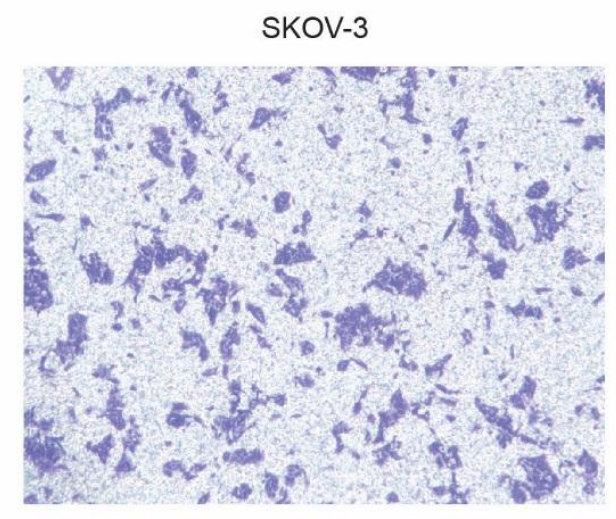

b

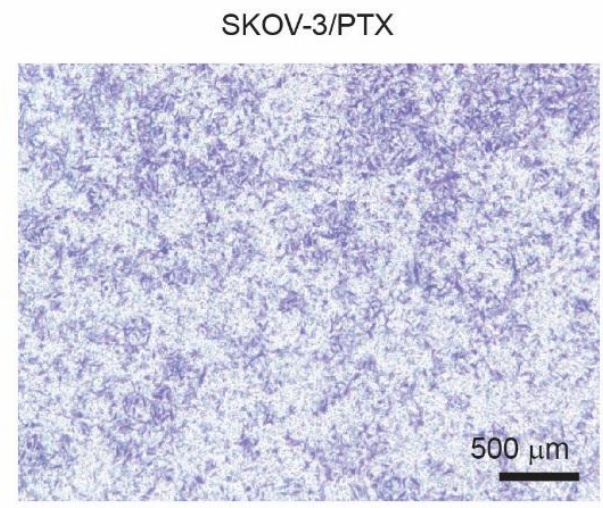

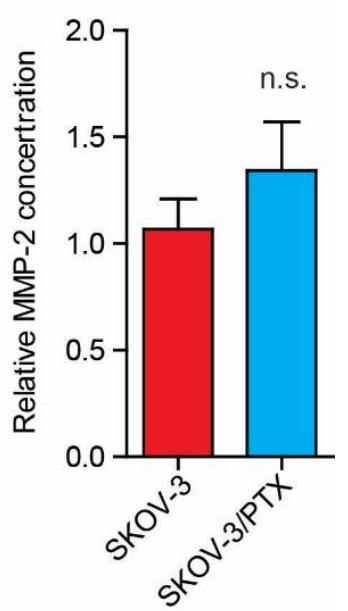

Figure s31. (a) The transwell assay was conducted to detect the invasive ability of SKOV-3 and SKOV-3/PTX cells. (b) MMP-2 expression in SKOV-3 and SKOV-3/PTX. n.s. not significant. 


\section{Figure s32}

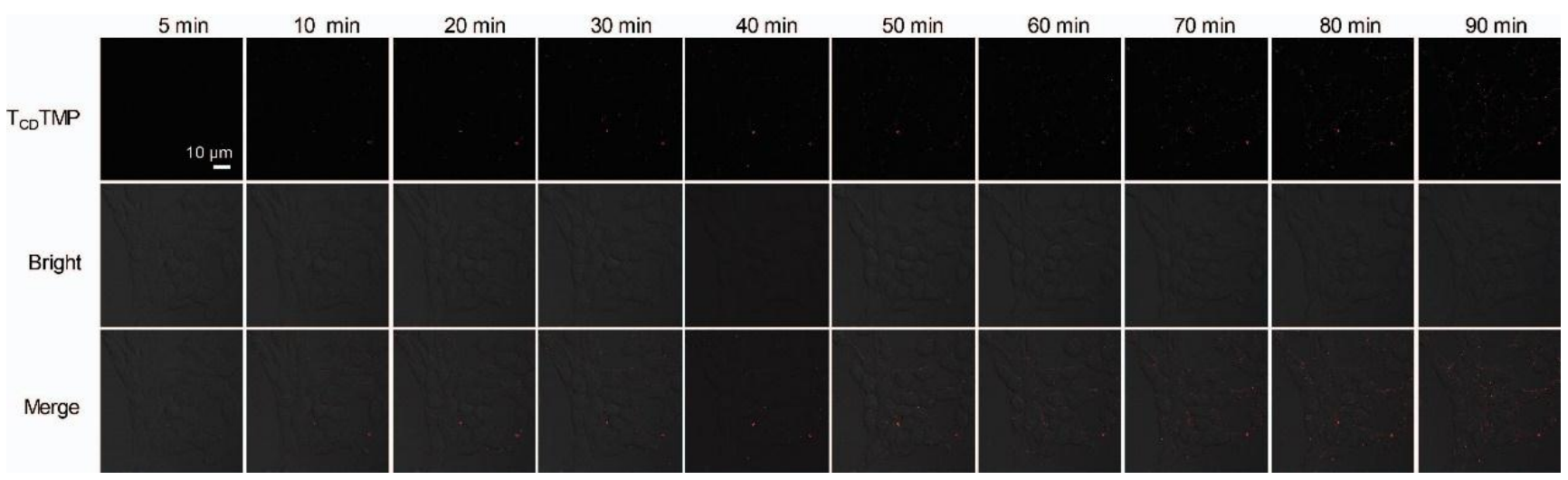

Figure s32. Real-time CLSM images of the SKOV-3 cells after incubated with $5 \mu \mathrm{M} \mathrm{T}_{\mathrm{CD}} \mathrm{TMP}$ for 5 , 10, 20, 30, 40, 50, 60, 70, 80 and 90 minutes, respectively. $\mathrm{T}_{\mathrm{CD}} \mathrm{TMP}$ channel: Excitation $488 \mathrm{~nm}$, Emission 660-700 nm. Scale bar: $10 \mu \mathrm{m}$. 
Figure s33

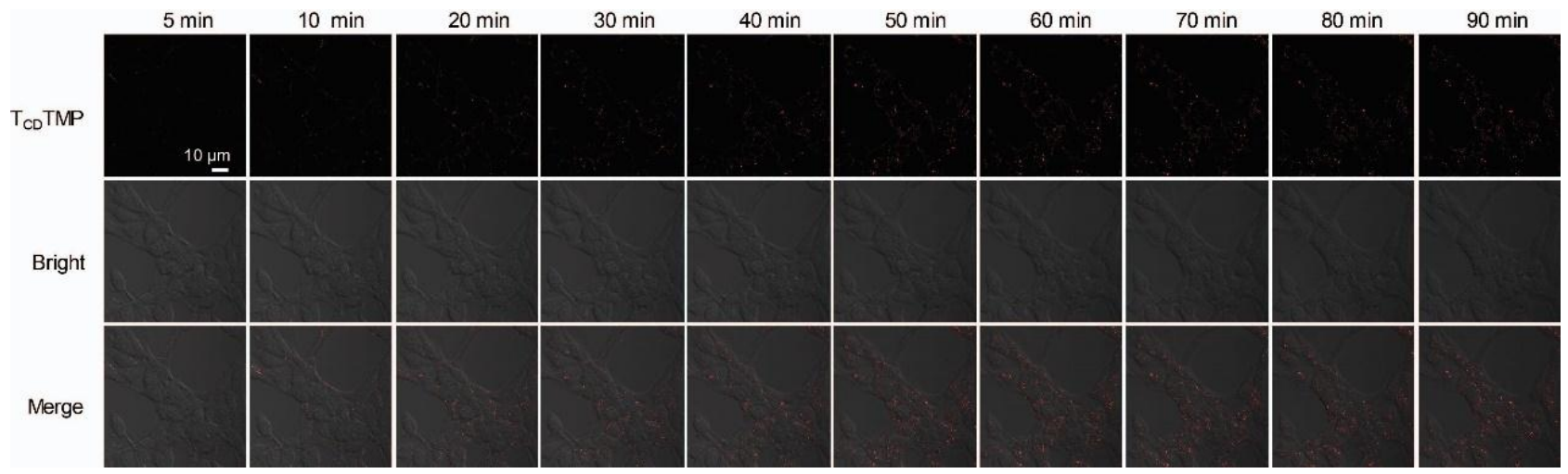

Figure s33. Real-time CLSM images of SKOV-3/PTX cells after incubated with $5 \mu \mathrm{M} \mathrm{T}_{\mathrm{CD}} \mathrm{TMP}$ for 5, 10, 20, 30, 40, 50, 60, 70, 80 and 90 minutes, respectively. $\mathrm{T}_{\mathrm{CD}} \mathrm{TMP}$ channel: Excitation $488 \mathrm{~nm}$, Emission 660-700 nm. Scale bar: $10 \mu \mathrm{m}$. 


\section{Figure s34}

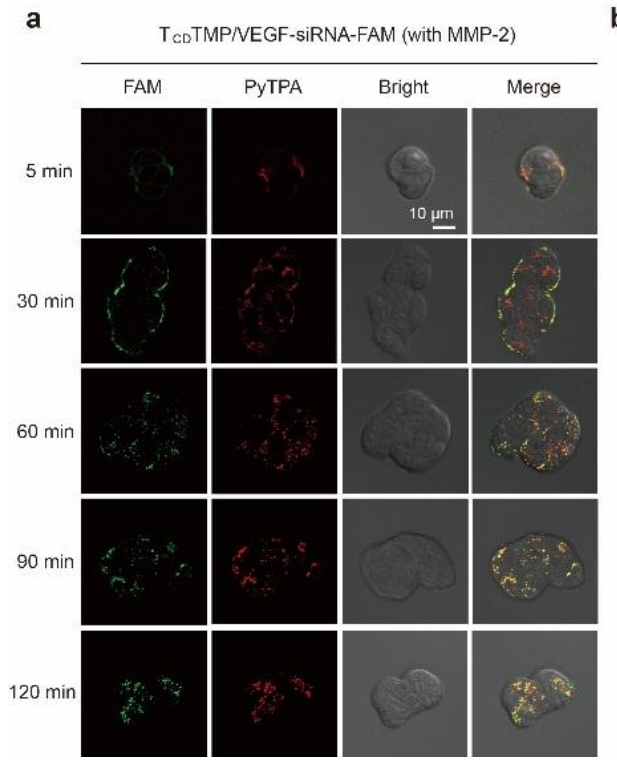

b

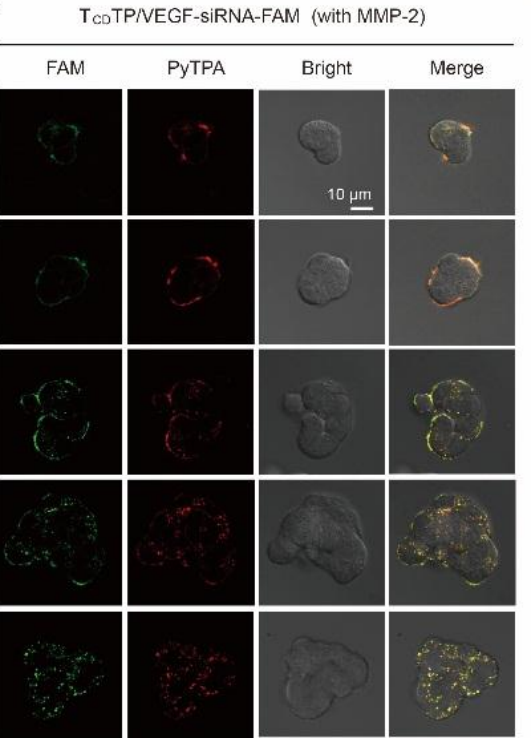

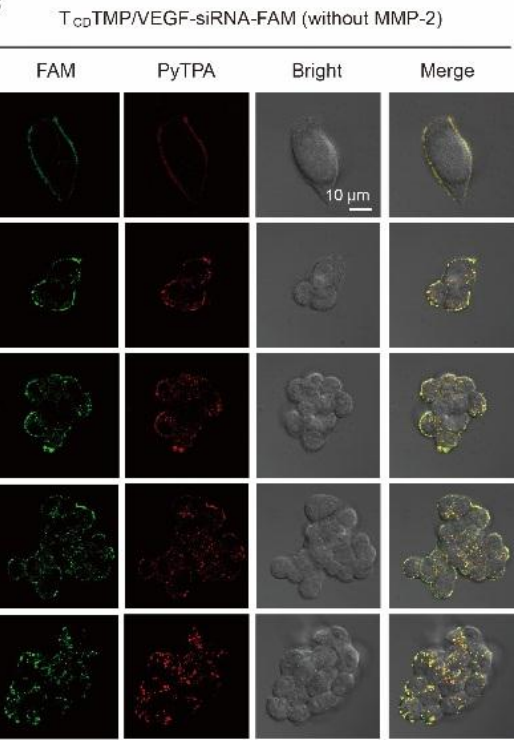

Figure s34. By incubation of SKOV-3/PTX cells with (a) TCDTMP/VEGF-siRNA-FAM or (b) $\mathrm{T}_{\mathrm{CD}} \mathrm{TP} / \mathrm{VEGF}$-siRNA-FAM nanoparticles at various times, the fluorescence of VEGF-siRNA-FAM and PyTPA was detected by CLSM. (c) After removing MMP-2 from SKOV-3/PTX cell culture medium and incubating $\mathrm{T}_{\mathrm{CD}} \mathrm{TMP} / \mathrm{VEGF}-\mathrm{siRNA-FAM}$ nanoparticles for different times, the fluorescence of VEGF-siRNA-FAM and PyTPA was detected by CLSM. FAM channel: Excitation $488 \mathrm{~nm}$, Emission 500-520 nm. PyTPA channel: Excitation $488 \mathrm{~nm}$, Emission 660-700 nm. Scale bars: $10 \mu \mathrm{m}$. 


\section{Figure s35}

a

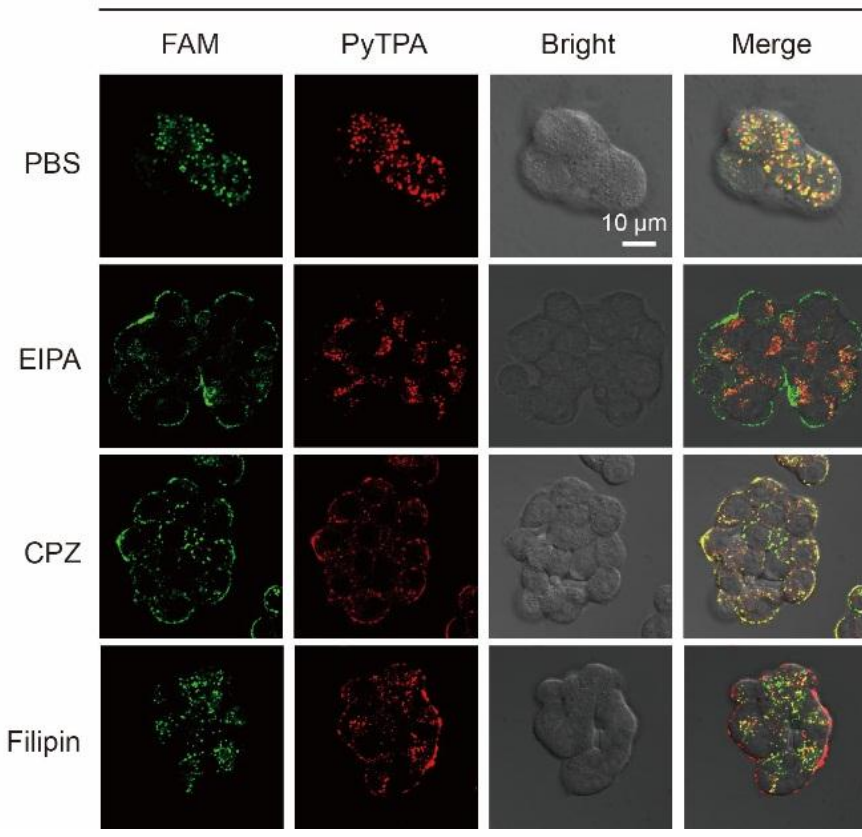

b

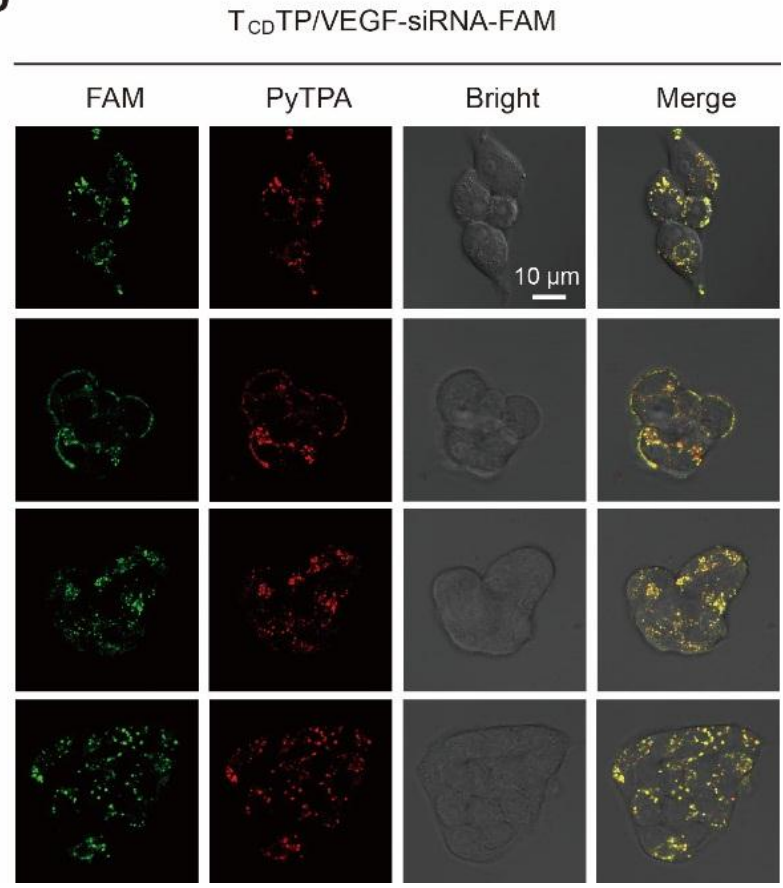

Figure s35. SKOV-3/PTX cells were pretreated with PBS, EIPA, CPZ and Filipin, respectively, and CLSM was used to detect the cellular uptake efficiency of (a) $\mathrm{T}_{\mathrm{CD}} \mathrm{TMP} / \mathrm{VEGF}-\mathrm{siRNA}-\mathrm{FAM}$ or (b) TCDTP/VEGF-siRNA-FAM. FAM channel: Excitation $488 \mathrm{~nm}$, Emission 500-520 nm. PyTPA channel: Excitation 488 nm, Emission 660-700 nm. Scale bars: $10 \mu \mathrm{m}$. 


\section{Figure s36}

a

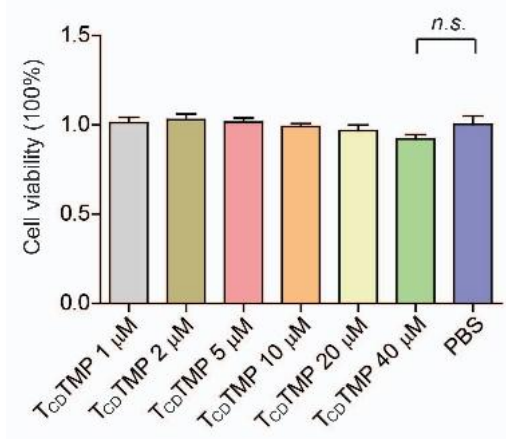

b

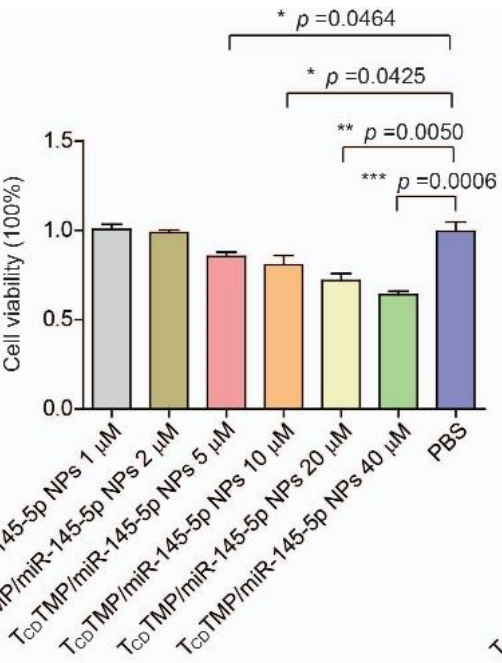

c

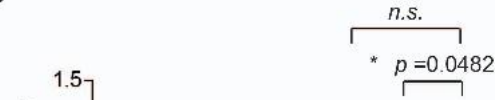

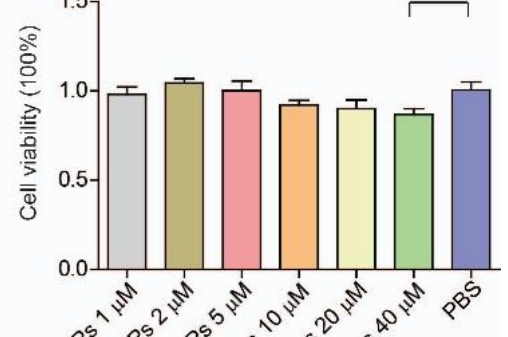

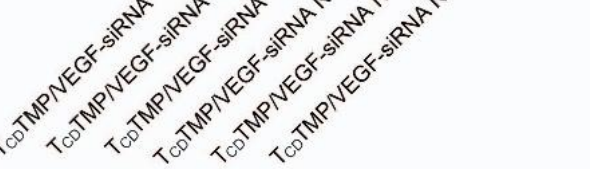

Figure s36. Cytotoxicity of $\mathrm{T}_{\mathrm{CD}} \mathrm{TMP}, \mathrm{T}_{\mathrm{CD}} \mathrm{TMP} / \mathrm{miR}-145-5 \mathrm{p}$ NPs and $\mathrm{T}_{\mathrm{CD}} \mathrm{TMP} / \mathrm{VEGF}-\mathrm{siRNA}$ NPs to SKOV-3/PTX cells. Data were reported as mean \pm SEM $(n=3)$ and analyzed by two-sided Student's t-test. $* p<0.05, * * p<0.01, * * * p<0.001$ n.s. not significant. 


\section{Figure s37}
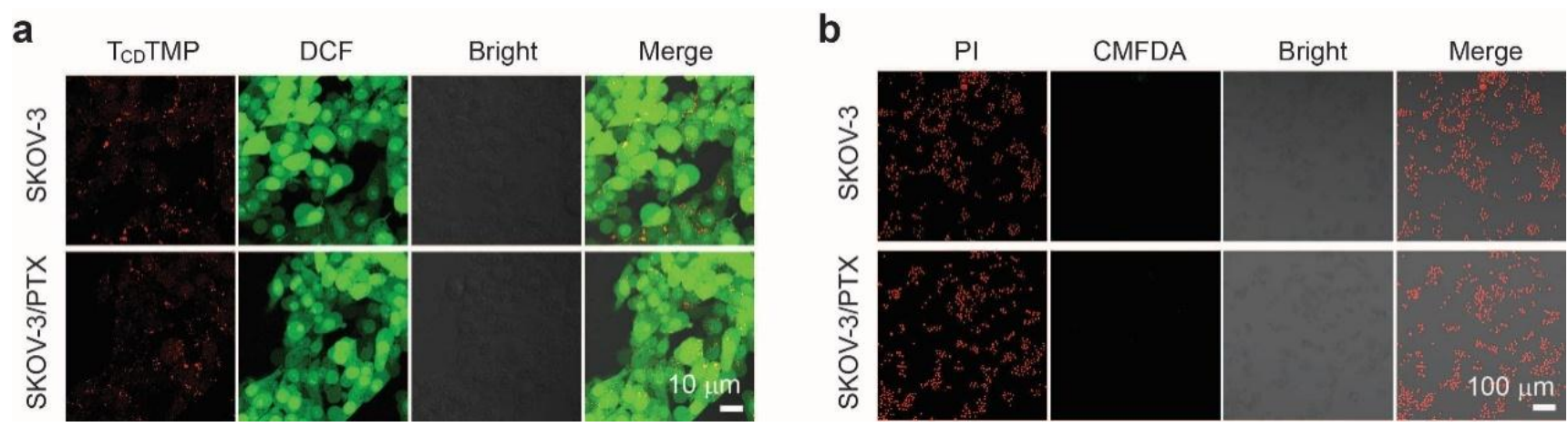

Figure s37. $\mathrm{T}_{\mathrm{CD}} \mathrm{TMP} / \mathrm{miR}-145-5 \mathrm{p}$ NPs-mediated PDT can efficiently kill SKOV-3 and SKOV-3/PTX cells. (a) DCFH-DA was conducted to detect the ROS levels in the cells after SKOV-3 and SKOV-3/PTX cells were incubated with $\mathrm{T}_{\mathrm{CD}} \mathrm{TMP} / \mathrm{miR}-145-5 \mathrm{p}$ NPs for 24 hours and irradiated $\left(100 \mathrm{~mW} / \mathrm{cm}^{2}\right)$ for 10 minutes. DCF channel: Excitation $488 \mathrm{~nm}$, Emission 500-560 nm;

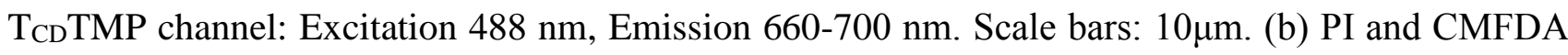
were used to determine the cell viability after SKOV-3 and SKOV-3/PTX cells were incubated with $\mathrm{T}_{\mathrm{CD}} \mathrm{TMP} / \mathrm{miR}-145-5 \mathrm{p}$ NPs for 24 hours and irradiated $\left(100 \mathrm{~mW} / \mathrm{cm}^{2}\right)$ for 10 minutes. PI channel: Excitation 543 nm, Emission 607-647 nm; CMFDA channel: Excitation 488 nm, Emission 500-560 nm. Scale bars: $100 \mu \mathrm{m}$. 


\section{Figure s38}
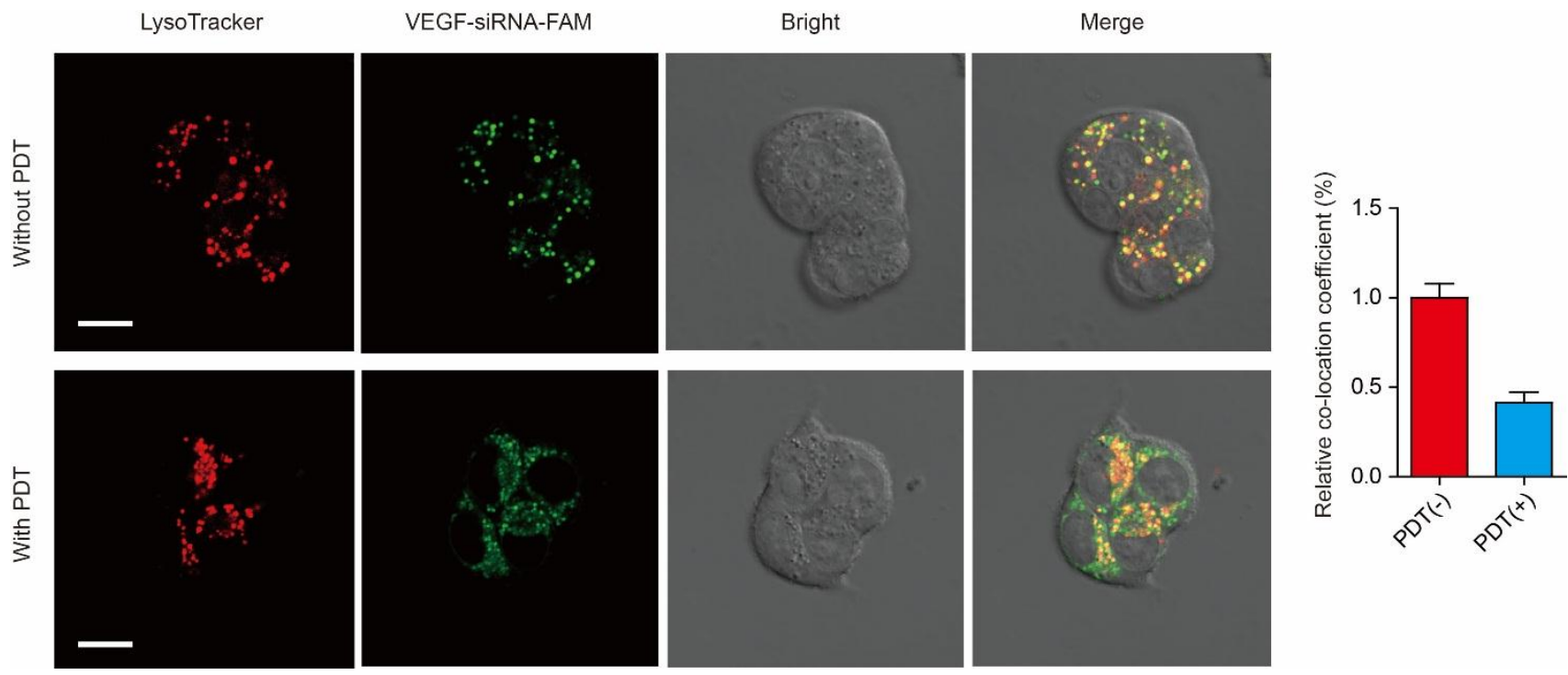

Figure s38. After incubation of SKOV-3/PTX cells with $\mathrm{T}_{\mathrm{CD}} \mathrm{TMP} / \mathrm{VEGF}-\mathrm{siRNA-FAM}$ for 4 hours, white light (50 mW/cm ${ }^{2}, 2$ minutes) was given. Cells were cultured for 1 hour and the distribution of VEGF-siRNA-FAM and lysosome was detected by CLSM. FAM channel: Excitation $488 \mathrm{~nm}$, Emission 500-540 nm. LysoTracker channel: Excitation 633 nm, Emission 640-700 nm. Scale bars: $20 \mu \mathrm{m}$. 


\section{Figure s39}

a

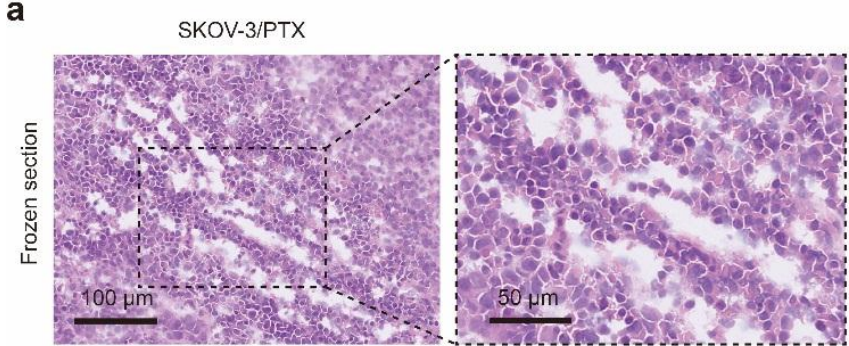

C

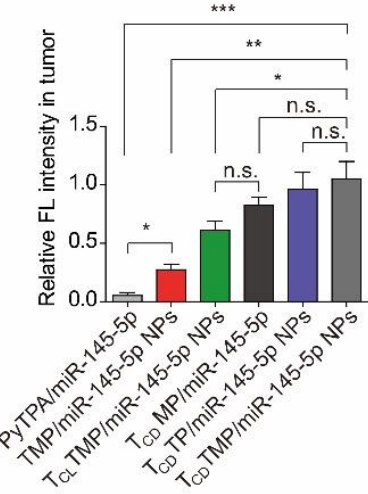

b

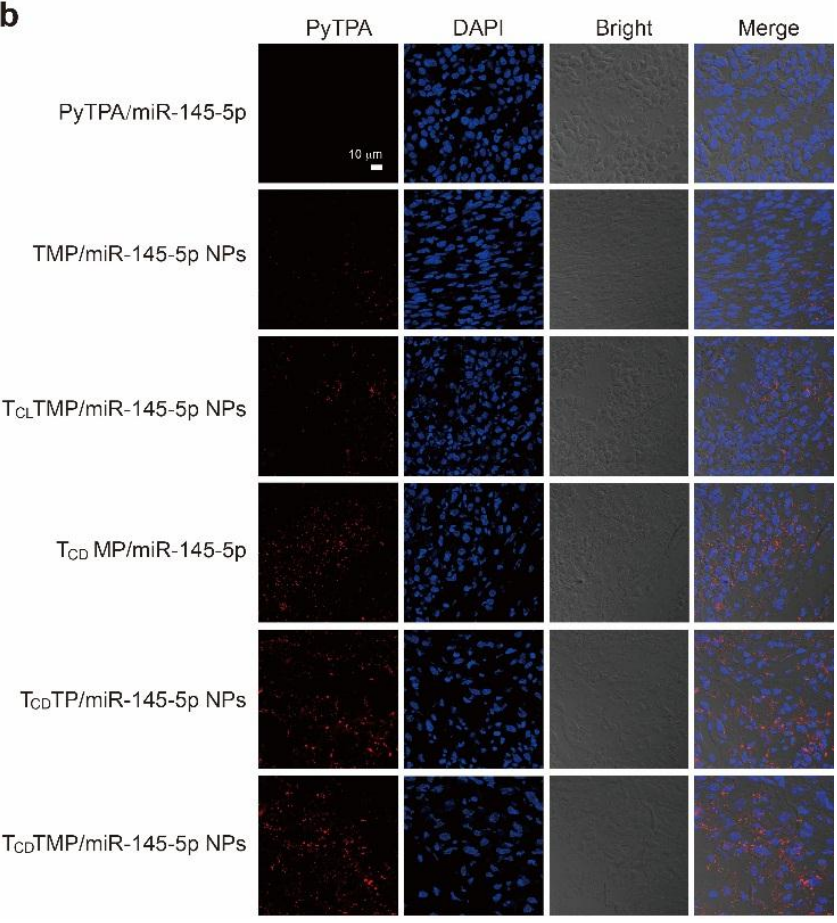

Figure s39. (a) The morphology of SKOV-3/PTX tumor tissue (frozen section). (b/c) The microdistribution of PyTPA/miR-145-5p, TMP/miR-145-5p, T ${ }_{\mathrm{CL}} \mathrm{TMP} / \mathrm{miR}-145-5 \mathrm{p}$, $\mathrm{T}_{\mathrm{CD}} \mathrm{MP} / \mathrm{miR}-145-5 \mathrm{p}, \mathrm{T}_{\mathrm{CD}} \mathrm{TP} / \mathrm{miR}-145-5 \mathrm{p}$ and $\mathrm{T}_{\mathrm{CD}} \mathrm{TMP} / \mathrm{miR}-145-5 \mathrm{p}$ in tumor was observed by CLSM. The data were represented as mean $\pm \operatorname{SEM}(\mathrm{n}=3)$ and analyzed by two-sided Student's t-test. $* p<0.05, * * p<0.01, * * * p<0.001$. PyTPA channel: Excitation $488 \mathrm{~nm}$, Emission 660-700 nm. DAPI channel: Excitation 405 nm, Emission 440-480 nm. Scale bar: $10 \mu \mathrm{m}$. 
Figure s40

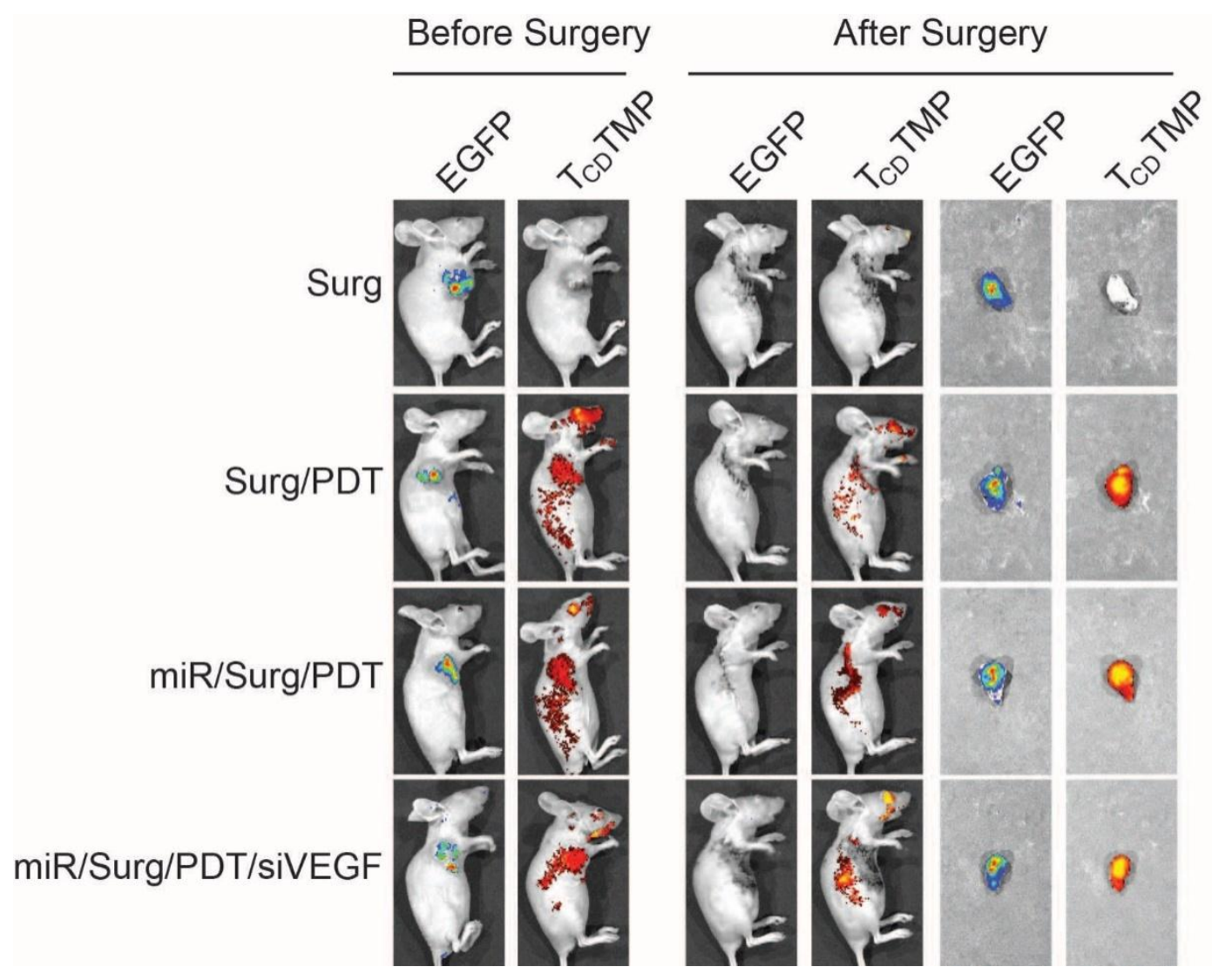

Figure s40. Fluorescence imaging of mice before and after surgical resection in the EGFP-SKOV-3/PTX subcutaneous xenograft model. EGFP: Excitation 500 nm, Emission $540 \mathrm{~nm}$. $\mathrm{T}_{\mathrm{CD}} \mathrm{TMP}$ : Excitation $465 \mathrm{~nm}$, Emission $680 \mathrm{~nm}$. 
Figure s41

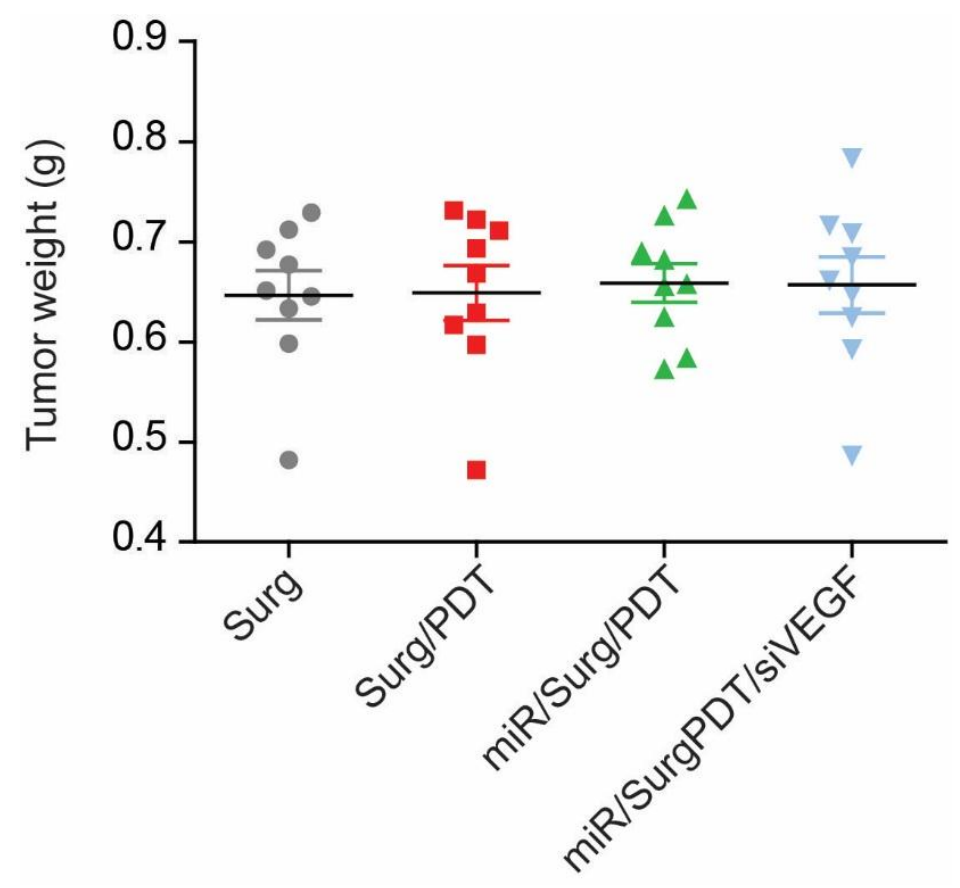

Figure s41. The weight of surgically resected tumors in Surg, Surg/PDT, miR/Surg/ PDT and $\mathrm{miR} / \mathrm{Surg} / \mathrm{PDT} / \mathrm{siVEGF}$ groups. Data were reported as mean $\pm \mathrm{SEM}(\mathrm{n}=10)$. 
Figure $\mathbf{4 2}$

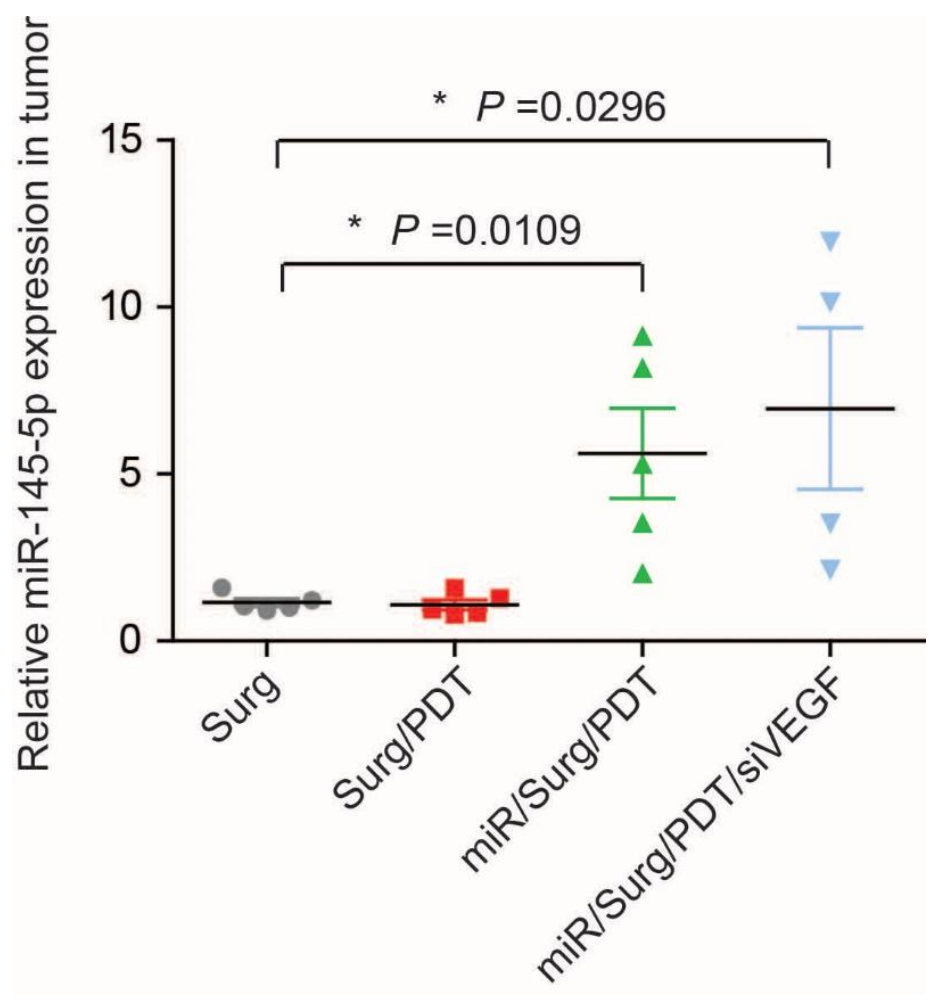

Figure s42. The expression levels of miR-145-5p in surgically resected tumor tissues in Surg, Surg/PDT, miR/Surg/PDT and miR/Surg/PDT/siVEGF groups. Data were reported as mean \pm SEM and analyzed by two-sided Student's t-test. * $P<0.05$. 


\section{Figure s43}

a

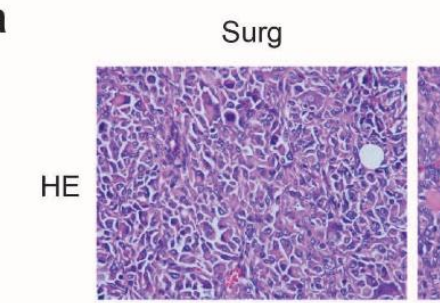

Surg/PDT
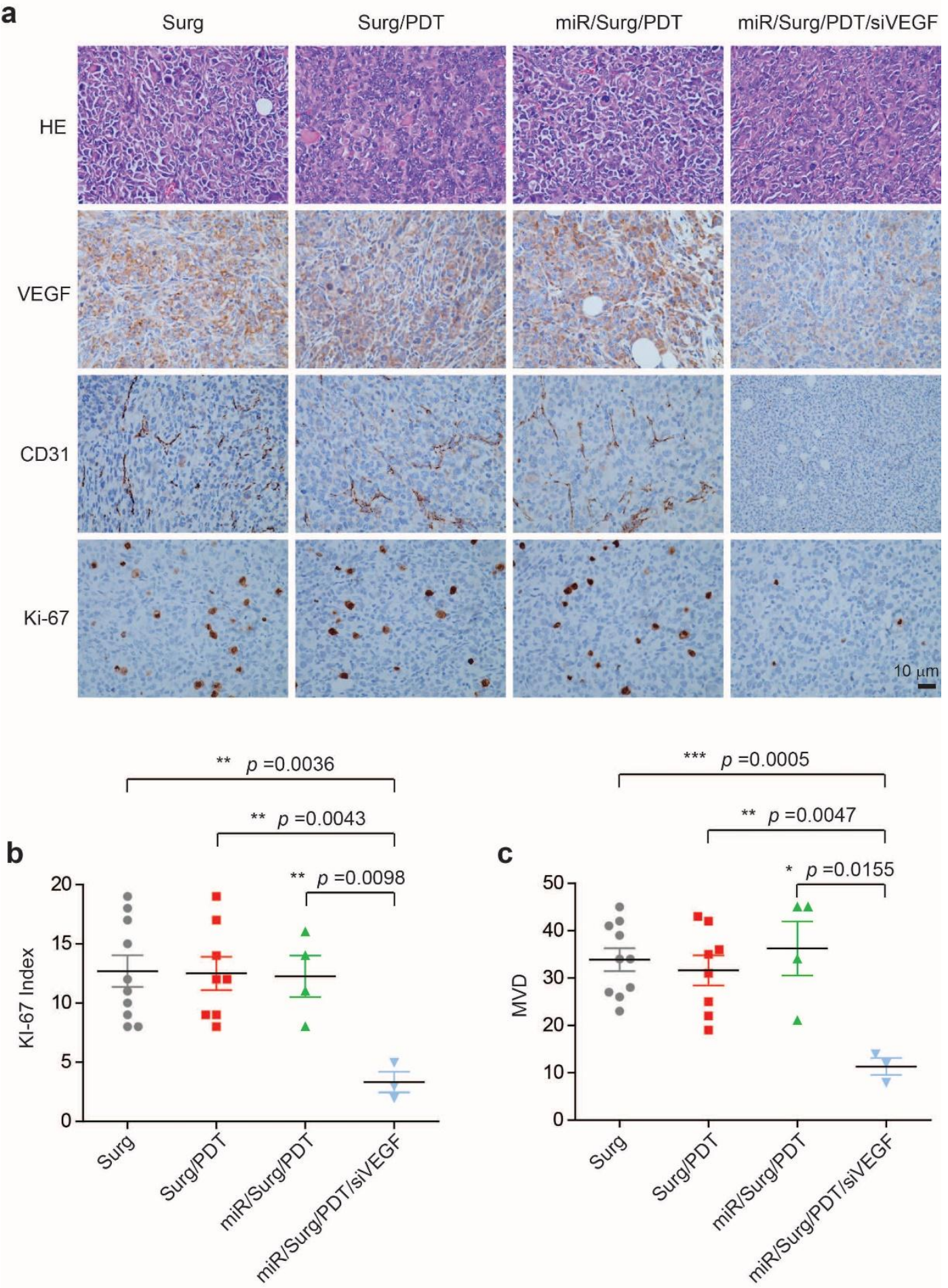

Figure s43. Histomorphology (a) and the expression of VEGF, CD31 and Ki-67 in recurrent tumors in Surg, Surg/PDT, miR/Surg/ PDT and miR/Surg/PDT/siVEGF groups. (b) and (c) represented the microvessel density and Ki-67 index of the recurrent tumor tissues in the four groups. Data were reported as mean $\pm \mathrm{SEM}$ and analyzed by two-sided Student's t-test. * $p<0.05$, ** $p<0.01$, *** $p<0.001$. 


\section{Figure s44}
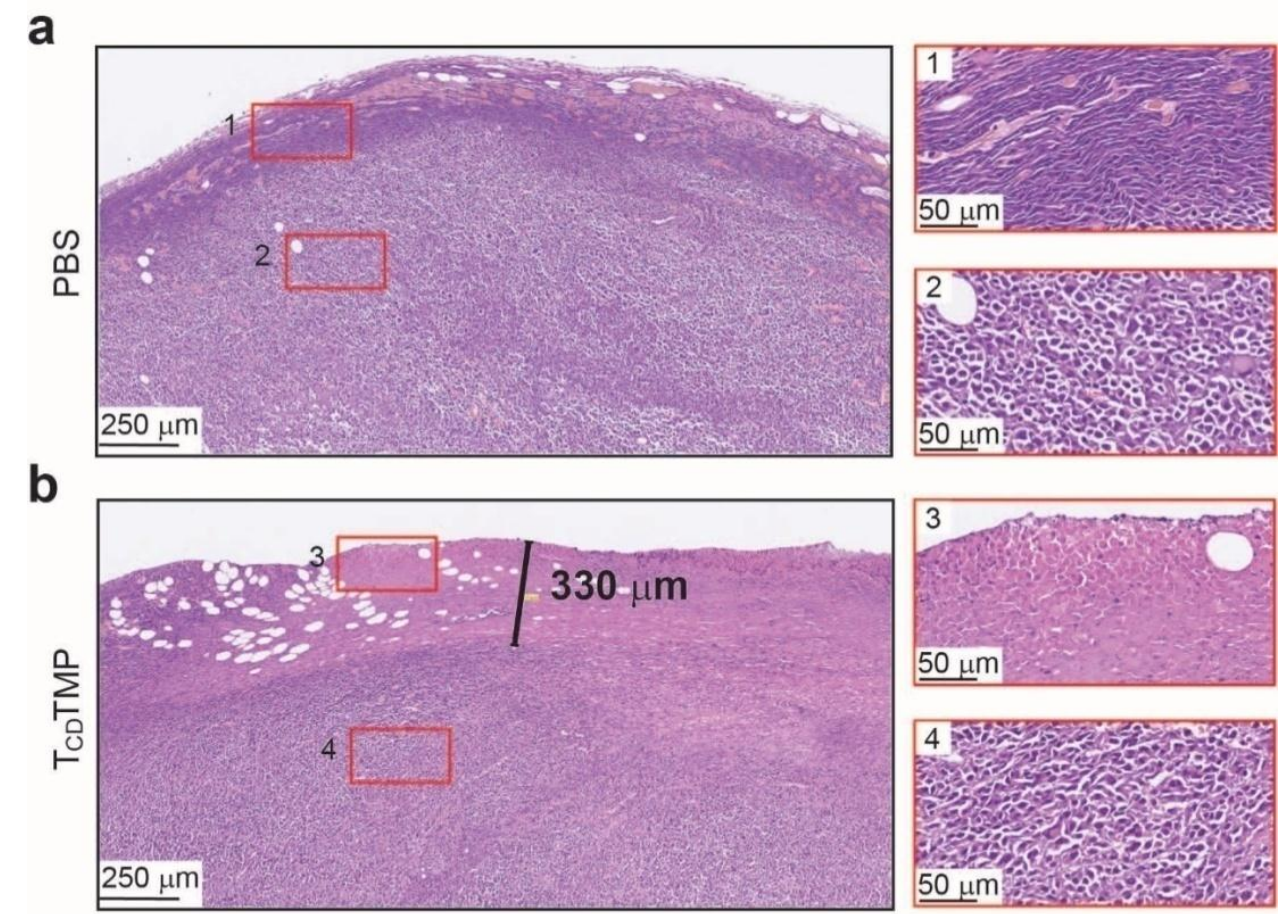

C
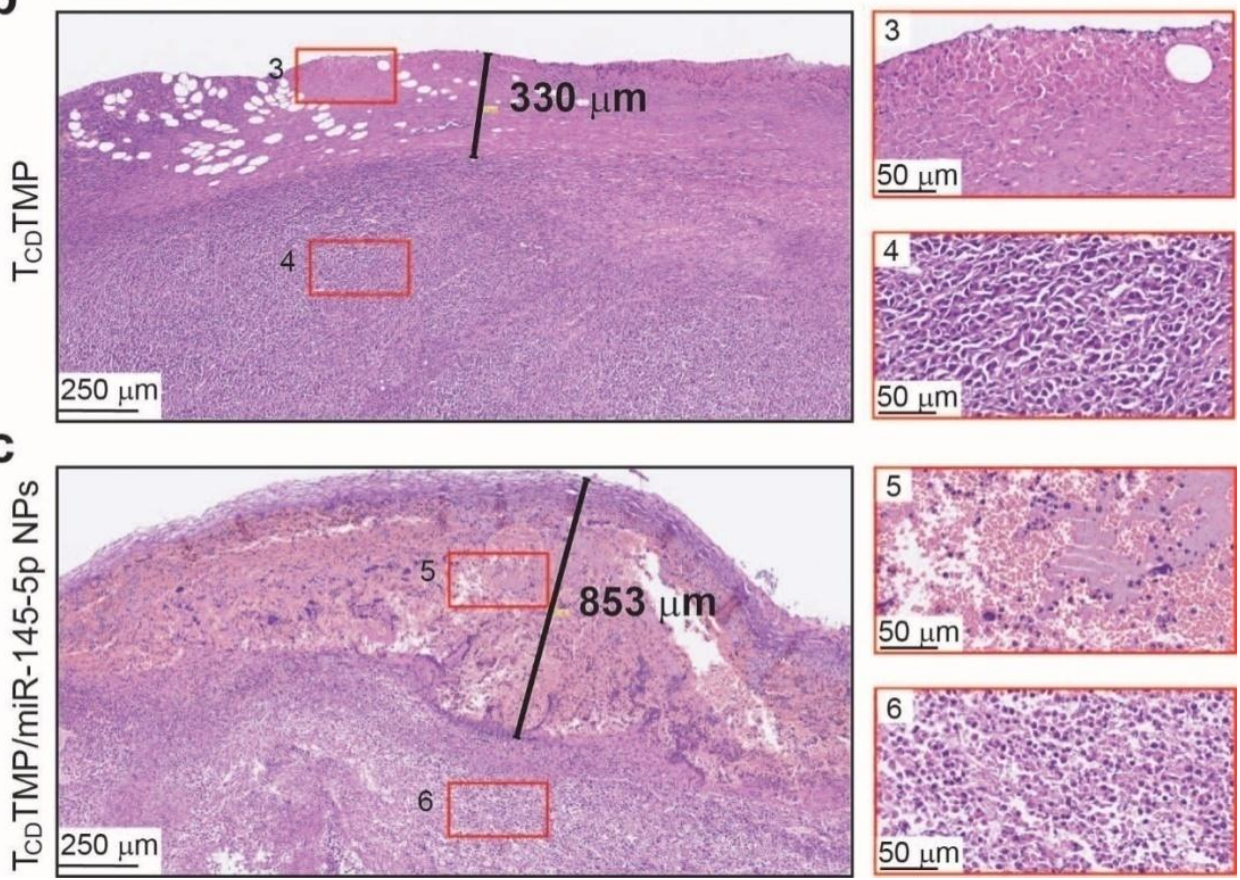

Figure s44. SKOV-3/PTX tumor-bearing mice were injected with PBS (a), $\mathrm{T}_{\mathrm{CD}} \mathrm{TMP}$ (b), $\mathrm{T}_{\mathrm{CD}} \mathrm{TMP} / \mathrm{miR}-145-5 \mathrm{p}$ NPs (c) via the tail vein, and irradiated with white light (intensity: $100 \mathrm{~mW} /$ $\mathrm{cm}^{2}$; time: 10 minutes) 24 hours later. After feeding for another 48 hours, the tumors were obtained and $H \& E$ staining was performed. Our results revealed no cell necrosis in the PBS group, superficial necrotic areas in the $\mathrm{T}_{\mathrm{CD}} \mathrm{TMP}$ group, while deeper necrotic areas in the $\mathrm{T}_{\mathrm{CD}} \mathrm{TMP} / \mathrm{miR}-145-5 \mathrm{p}$ NPs group. 